\title{
COMPORTAMIENTO NO LINEAL DE MARCOS DÚCTILES DE CONCRETO REFORZADO CON CONTRAVENTEO METÁLICO CHEVRÓN. PROPUESTA DE DISEÑO
}

\author{
Eber A Godinez Dominguez ${ }^{(1)}$ y Arturo Tena Colunga ${ }^{(2)}$
}

\begin{abstract}
RESUMEN
Se presenta un estudio en que se evalúa, mediante análisis estáticos no lineales ante carga monótona creciente, el comportamiento de marcos dúctiles de concreto reforzado con contraventeo metálico tipo chevrón de entre cuatro y 24 niveles ubicados en la zona del lago del Distrito Federal. El estudio representa la primera etapa de una investigación integral, enfocada tanto a la obtención de parámetros específicos para el diseño del sistema estructural estudiado, como en la evaluación de una metodología de diseño por capacidad adaptada de los lineamientos de las Normas Técnicas Complementarias del Reglamento de Construcciones para el Distrito Federal vigente. Con base en el conjunto de resultados analíticos, se proponen algunos parámetros específicos para el diseño de estructuras nuevas, como son: distorsiones de fluencia, distorsiones de diseño asociadas al estado de prevención de colapso, factores de reducción por sobrerresistencia y aporte mínimo de las columnas al cortante del sistema resistente ante carga lateral. Asimismo, se evalúa la metodología de diseño propuesta mediante el estudio detallado de los diferentes miembros estructurales. Finalmente, se hacen algunos comentarios puntuales a las disposiciones de las NTCS-04.
\end{abstract}

Palabras clave: marcos dúctiles contraventeados, contraventeo metálico chevrón, diseño por capacidad, distorsiones de diseño, factor de reducción por sobrerresistencia, desempeño estructural.

\begin{abstract}
In this paper the authors summarize the results of a study devoted to evaluate, using static nonlinear analyses, the behavior of ductile moment-resisting reinforced concrete concentric braced frames structures (RC-MRCBFs) using chevron steel bracing (4 to 24 stories). RC-MRCBFs were assumed to be located in soft soil conditions in Mexico City. The study represents the first stage of a project devoted to obtain specific design parameters of this dual system as well as to evaluate a capacity design methodology adapted from the current guidelines of the Mexican Federal District Code (MFDC). From the results obtained, some design parameters for the new design of RC-MRCBFs are proponed, as equivalent story drift at yielding, peak story drifts, overstrength factors and minimum required shear strength of the columns for the lateral-load resisting system. Also, the design methodology is evaluated using a detailed study of different structural members. Finally, some comments are made respect to specific recommendations of NTCS-04.
\end{abstract}

Artículo recibido el 1 de diciembre de 2010 y aprobado para su publicación el 2 de septiembre de 2011. Se aceptarán comentarios y/o discusiones hasta cinco meses después de su publicación.

(1) Profesor, Facultad de Ingeniería, Universidad Autónoma de Chiapas, Campus-I, Blvd. Belisario Domínguez, kilómetro 1081, Sin número, Col. Terán, 29050, Tuxtla Gutiérrez, Chiapas, México, e-mail: eber.godinez@unach.mx

(2) Profesor, Departamento de Materiales, Universidad Autónoma Metropolitana Azcapotzalco, Av. San Pablo 180, Col. Reynosa Tamaulipas, 02200 México, DF, e-mail: atc@,correo.azc.uam.mx 
Keywords: ductile braced frames, chevron steel bracing, capacity design, design drifts, overstrength factor, structural performance.

\section{INTRODUCCIÓN}

Durante décadas se ha recurrido al empleo de contravientos metálicos como sistema de reparación para el incremento de la rigidez y resistencia a fuerza cortante de estructuras dañadas por sismo. Existen numerosos estudios en que se muestra la eficiencia de este esquema de reparación para limitar el daño producto de eventos sísmicos, así como para incrementar la rigidez y resistencia de estructuras con base en marcos de concreto reforzado (Del Valle et al. 1988, Foutch et al. 1989, Badoux y Jirsa 1990, Downs et al. 1991, Masri y Goel 1996, Tena et al. 1996, Ghobarah y Abou-Elfath 2001 y Osman et al. 2006).

Dado el buen comportamiento observado de las estructuras con base en marcos de concreto reestructuradas tanto en México como alrededor del mundo empleando contravientos metálicos, y al hecho de que esta estructuración se propone en las Normas de Diseño por Sismo desde hace décadas, considerando incluso la posibilidad de que el comportamiento sea dúctil, se considera necesario valorar metodologías de diseño para estructuras nuevas que consideren que una estructuración con base en marcos de concreto reforzado con contravientos concéntricos pueda comportarse dúctilmente. Asimismo, se requiere de la obtención de parámetros de diseño específicos que representen y predigan de la mejor manera posible el comportamiento del sistema estructural en estudio.

En años recientes el empleo de marcos de concreto reforzado contraventeados se ha estudiado no únicamente desde un enfoque de reparación, sino desde el punto de vista de diseño de edificaciones nuevas. Algunos investigadores se han enfocado en el estudio del comportamiento sísmico y el desarrollo de parámetros de diseño para diferentes configuraciones de contraventeo (Maheri y Akbari 2003, Maheri y Hadjipour 2003, Youssef et al. 2007, Godínez y Tena 2007, Godínez y Tena 2008, Maheri y Ghaffarzadeh 2008, Godínez y Tena 2009, Godínez y Tena 2010 y Godínez 2010).

En este estudio se presentan tanto aspectos relevantes del comportamiento a nivel local y global, como parámetros que se consideran útiles para el diseño de estructuras nuevas con base en marcos de concreto reforzado con contraventeo metálico tipo chevrón. Los parámetros de diseño se obtuvieron a partir de los resultados de análisis estáticos no lineales ante carga monótona creciente de modelos entre cuatro y 24 niveles. El diseño de cada uno de los modelos en estudio se realizó empleando una metodología de diseño por capacidad adaptada de los lineamientos de las Normas Técnicas Complementarias del Reglamento de Construcciones para el Distrito Federal en su versión 2004, la cual se resume en secciones posteriores.

Entre los resultados obtenidos que se presentan se destacan: a) mapeos de rotaciones plásticas acumuladas obtenidos para los marcos estudiados $(4,8,12,16,20$ y 24 niveles) asociados al estado de prevención de colapso, b) comportamiento de los sistemas acorde a los balances de resistencia a fuerza cortante entre columnas y contravientos, c) capacidades de deformación globales y de entrepiso, d) distorsiones de fluencia de entrepiso, e) propuesta de un límite de distorsión correspondiente al estado límite de servicio, f) propuesta de un límite de distorsión correspondiente al estado límite de prevención de colapso, g) niveles de sobrerresistencia mínimos y máximos esperados, h) propuesta de una expresión para el cálculo de los factores de reducción por sobrerresistencia y, i) propuesta del aporte mínimo de las columnas a la resistencia a fuerza cortante de entrepiso del sistema resistente ante carga lateral en función de la relación de esbeltez. 
A partir del análisis de los resultados obtenidos con los modelos no lineales empleados, se discute sobre algunos aspectos complementarios que sería adecuado incluir en futuras versiones de las Normas Técnicas Complementarias para Diseño de Estructuras de Concreto, así como para las Normas Técnicas Complementarias para Diseño por Sismo, con la finalidad de garantizar un comportamiento razonablemente dúctil en dichos sistemas. Se concluye además, que si se desea obtener un diseño en que lidere un mecanismo de colapso columna fuerte - viga débil - contraviento más débil, es necesario aplicar conceptos de diseño por capacidad, donde se diseña en primera instancia el contraviento (el elemento más débil), después la viga (el segundo elemento más débil), posteriormente la columna y, finalmente, revisar el esquema de conexión que permita salvaguardar la integridad del nudo y diseñarlo adecuadamente.

Como se mencionó, el estudio representa la primera etapa de una investigación integral. En la segunda etapa del estudio (Godínez 2010) se evaluó el comportamiento de edificios diseñados conforme a las propuestas realizadas en este artículo. La evaluación del comportamiento de los edificios diseñados se realizó mediante análisis dinámicos no lineales paso a paso y los resultados de dicho estudio serán publicados en esta misma revista tan pronto sea posible (Godínez et al. 2012).

\section{REQUISITOS REGLAMENTARIOS}

Actualmente existen algunas limitaciones en el Reglamento de Construcciones del Distrito Federal y sus correspondientes Normas Técnicas Complementarias, así como en algunos otros códigos de diseño internacional (por ejemplo, ACI-318 2008 y ASCE 7-05 2005) para el diseño de estructuras dúctiles con base en marcos de concreto reforzado con contraventeo metálico. Por ejemplo, en las actuales Normas Técnicas Complementarias para Diseño de Estructuras de Concreto (NTCC-04) no se hace referencia cruzada a las Normas Técnicas Complementarias para Diseño de Estructuras Metálicas (NTCM-04) para el diseño de estas estructuras duales, únicamente se contempla el empleo de contravientos de concreto reforzado. Asimismo, los lineamientos de las NTCC-04 no consideran la posibilidad de tener nudos a los cuales llegan contravientos y, por ello, no existen guías específicas de cómo revisarlos y diseñarlos. No se establece cómo revisar un nudo donde se reducen notablemente los giros $\mathrm{y}$, por ello, los momentos flexionantes y las respectivas fuerzas cortantes que se transmitirían al nudo por parte de vigas y columnas, ni se dan guías de cómo revisar la transmisión de las fuerzas axiales de los contravientos al nudo, las que dependen en mucho del esquema de conexión que se quiera utilizar, si se usa una conexión donde se tiende a concentrar la fuerza axial, o si se elige un esquema de conexión donde se distribuye la fuerza del contraviento de manera más uniforme en la vecindad del nudo, a través de vigas y columnas. En algunos casos, no se limita la contribución del sistema de contraventeo a la resistencia a fuerza cortante de un entrepiso, lo cual impacta directamente en la capacidad a deformación del sistema dual y define si su comportamiento puede o no llegar a ser dúctil. Es notoria la ausencia de guías específicas de diseño que garanticen el comportamiento dúctil de estos sistemas estructurales, por lo que no se puede garantizar el mecanismo de falla esperado columna fuerte-viga débil-contraviento más débil.

De acuerdo con las Normas Técnicas Complementarias para Diseño por Sismo (NTCS-04), las estructuras con base en marcos contraventeados deben analizarse considerando la contribución de la resistencia a fuerza cortante tanto del marco como del sistema de contraventeo (figura 1). En el caso de estructuras con comportamiento dúctil, en cada entrepiso los marcos deben ser capaces de resistir, sin contar con contravientos, cuando menos el 50 por ciento de la fuerza sísmica actuante.

Para valorar la pertinencia de este límite, que se propuso más con base en la intuición y en la experiencia que en estudios específicos, se realizaron estudios en que se diseñaron marcos que, además de cumplir con este balance, satisficieran dos balances más, uno que no cumple con esta recomendación (las 
columnas de los marcos resisten aproximadamente el 25\%) y otro que excede esta recomendación (las columnas de los marcos resisten aproximadamente el 75\%).

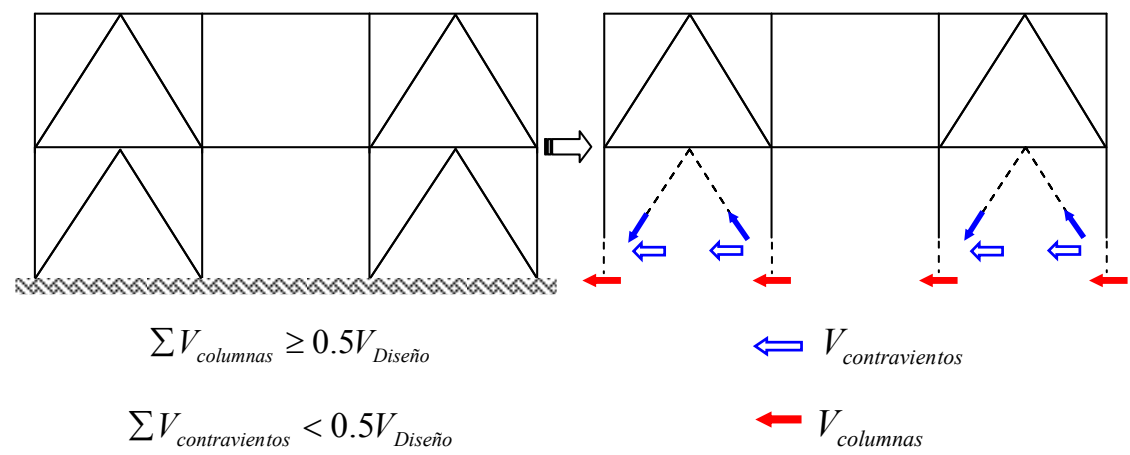

Figura 1. Mecanismo resistente a fuerza cortante en marcos contraventeados de acuerdo con las NTCS-04

\section{MODELOS Y CASOS DE ESTUDIO}

\section{Descripción de los modelos de análisis}

Los marcos analizados corresponden a una estructura regular tridimensional con uso supuesto para albergar oficinas. El edificio cuenta con una planta rectangular de $21 \mathrm{~m}$ de ancho (dirección $Y$ ) y $32 \mathrm{~m}$ de largo (dirección $X$ ) en la que los marcos periféricos se encuentran contraventeados en sus crujías exteriores. El edificio cuenta con cuatro crujías en la dirección $X$ y tres en la dirección $Y$ con claros de $8 \mathrm{~m}$ y $7 \mathrm{~m}$ respectivamente (figura 2). En la dirección $X$ existen vigas secundarias. La altura típica de entrepiso es de $3.40 \mathrm{~m}$. Por lo tanto, las alturas totales de los modelos de 4, 8, 12, 16, 20 y 24 niveles son 13.6, 27.2, 40.8, 54.4, 68.0 y 81.6 m respectivamente. Esta configuración estructural ha sido empleada en estudios previos de marcos dúctiles de concreto reforzado (Luaces 1995, Tena et al. 1997, Luna 2000, Correa 2005, Gatica 2007, Tena et al. 2008).

La gama de alturas estudiada permitió obtener resultados representativos para un intervalo de periodos amplio, lo cual es deseable para un mejor entendimiento del comportamiento estructural conforme se incrementa la altura de los marcos y valorar cómo impacta la esbeltez $(H / L)$ en el comportamiento sísmico de estructuras que cumplen con el resto de las condiciones de regularidad.

\section{Casos de estudio}

Se analizaron marcos planos considerando distintas variantes, basadas en el aporte que a la resistencia ante carga lateral brindan las columnas con respecto a los contravientos. Como se comentó, lo anterior se hizo en atención a lo estipulado en las NTCS-04, donde se establece que para el empleo de un factor de comportamiento sísmico $Q=4$ (adoptado en el diseño de todos los modelos) en estructuras cuya resistencia en todos los entrepisos es suministrada por marcos contraventeados, en cada entrepiso los marcos deben ser capaces de resistir, sin contar con contravientos, cuando menos el 50 por ciento de la fuerza sísmica actuante (figura 1). 
Los casos considerados son tres:

Caso I. Cuando las columnas de los marcos resisten un porcentaje menor al $50 \%$ de la carga sísmica actuante (aproximadamente 25\%), lo cual no está permitido en las NTCS-04 para comportamiento dúctil.

Caso II. Cuando la condición estipulada en las NTCS-04 para comportamiento dúctil se cumple al límite, es decir, el 50\% de la carga actuante es resistida por las columnas de los marcos y el $50 \%$ por los contravientos.

Caso III. Cuando un porcentaje mayor de carga lateral es resistida por las columnas de los marcos (aproximadamente 75\%).

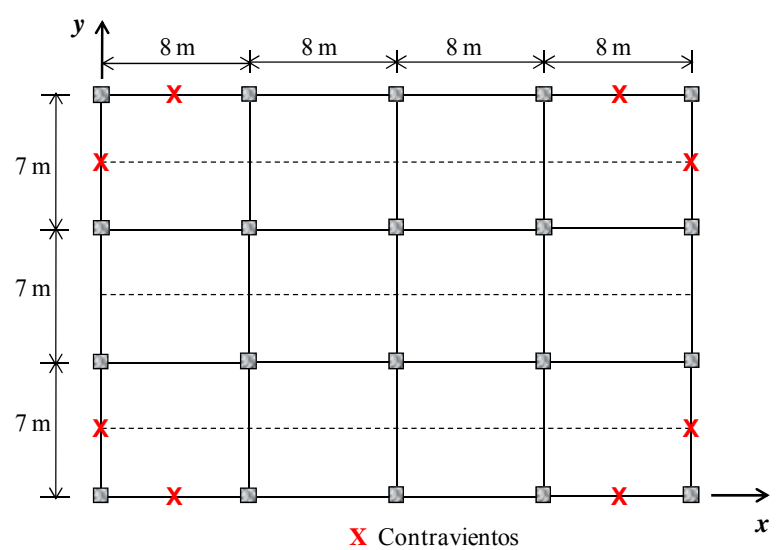

a) Planta
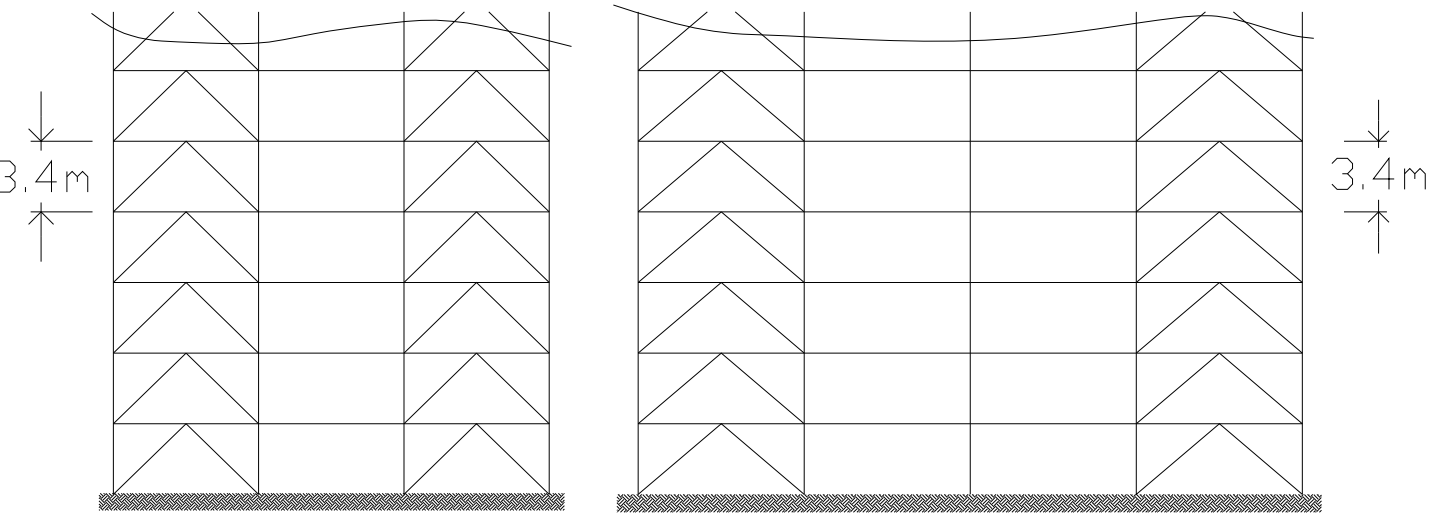

b) Elevaciones de los marcos en dirección $Y$ e $X$

Figura 2. Planta y elevaciones de los modelos estudiados

Este planteamiento se realizó con la finalidad de estudiar si el balance de resistencia estipulado en las NTCS-04 es razonable o no para obtener un comportamiento dúctil, y valorar cómo dicho balance puede afectar el comportamiento estructural del sistema, tanto a nivel global como a nivel local. 


\section{METODOLOGÍA DE DISEÑO}

Los modelos para el análisis estructural se realizaron con el programa de análisis SAP2000 en su versión 7.12 (SAP2000 1999). Para el cálculo de las fuerzas laterales para el diseño de los marcos se llevó a cabo un análisis modal espectral, incluyendo los efectos $P-\Delta$, cuidando en cada caso lo estipulado en las NTCS-04 referente a que en cada caso el cortante basal obtenido mediante un análisis dinámico no debe ser menor al $80 \%$ del cortante basal calculado mediante un análisis estático.

\section{Consideraciones para el análisis estructural}

En esta investigación, para la elaboración de los modelos de análisis estructural se consideró el aporte de la losa en rigidez y resistencia, es decir, al modelar las vigas, éstas se hicieron como vigas L en el caso de los marcos perimetrales, o en su caso vigas T. Las losas fueron previamente diseñadas, como es costumbre, para tomar cargas verticales y satisfacer estados límites de deformación y de servicio (Gatica 2007). Asimismo, de acuerdo con lo recomendado en la literatura (por ejemplo, Horvilleur y Cheema 1994, Tena 2007), en los análisis se consideró que la rigidez en los nudos es $50 \%$ de la que tendrían si fueran infinitamente rígidos a flexión, además de ser una hipótesis comúnmente empleada para el diseño de estructuras con base en marcos de concreto reforzado, según una encuesta realizada a diferentes despachos prestigiados de diseño estructural (Fuentes 2000).

Asimismo, no se aplicó la disposición de la sección 1.3.1 de las NTCC-04 referente a considerar secciones agrietadas en la elaboración de los modelos de análisis estructural; es decir, se emplearon las propiedades de secciones gruesas, por las razones que se comentan en detalle en Tena y Correa (2007) y Tena et al. (2008). Lo anterior se debe a que dicha disposición no toma en cuenta que toda estructura nueva o que no haya sido afectada por un sismo importante se encuentra prácticamente intacta y/o sin un nivel de agrietamiento que justifique una reducción de la inercia de sus vigas de hasta un $50 \%$ (asociado a un agrietamiento importante y visible), y es precisamente en estas condiciones que debe resistir su primera excitación sísmica. En efecto, como se comenta en los trabajos de referencia, la aplicación generalizada e irreflexiva de dicha disposición podría conducir en algunos casos a diseños inseguros y/o en otros a unos muy conservadores.

Esta modelación, propuesta en las NTCC-04 y otros reglamentos internacionales como el ACI-08 (ACI-08 2008) es discutible, pues entre otras cosas, la degradación de rigidez de las vigas de los marcos en elevación y en planta no es uniforme. Cabe señalar que una pérdida del $50 \%$ de la rigidez de las vigas está asociada a rotaciones plásticas y agrietamientos importantes, observables a simple vista, y no a las pequeñas fisuras por contracción, a lo cual algunos diseñadores pretenden asociar de manera errónea todas las diferencias observadas entre la rigidez inicial medida en algunos experimentos con respecto a la estimada analíticamente, pasando por alto que estas diferencias también están asociadas a muchos otros factores, entre ellos las incertidumbres en la estimación de las propiedades "reales" del concreto, como el módulo de elasticidad.

\section{Espectros para diseño sísmico}

Las estructuras en estudio se ubicaron para su diseño en la subzona III-b, pues a ésta le corresponden las mayores demandas sísmicas (mayor coeficiente sísmico) de acuerdo a lo estipulado en las NTCS-04. Para la definición del espectro de diseño sísmico del cuerpo principal de las NTCS-04 se obtuvo un coeficiente de aceleración del terreno $a_{0}=0.11$, un coeficiente sísmico $c=0.45 \mathrm{y}$ los periodos característicos $T_{a}=0.85 \mathrm{~s}$ y $T_{b}=3.0 \mathrm{~s}$, así como un valor $r=2$. 
En la figura 3 se muestra el espectro elástico de diseño sísmico del cuerpo principal, así como el reducido por concepto de ductilidad para $Q=4$ (factor de comportamiento sísmico empleado en los diseños).

Debido a las diferencias en altura de los modelos estudiados, las demandas a las que estará sujeto cada uno de ellos dependerán de sus características dinámicas (periodo). La mayoría de los modelos de mayor altura (12 a 24 niveles), se encuentran ubicados en la meseta del espectro (tabla 1), lo cual indica que estarán sujetos a las máximas demandas.

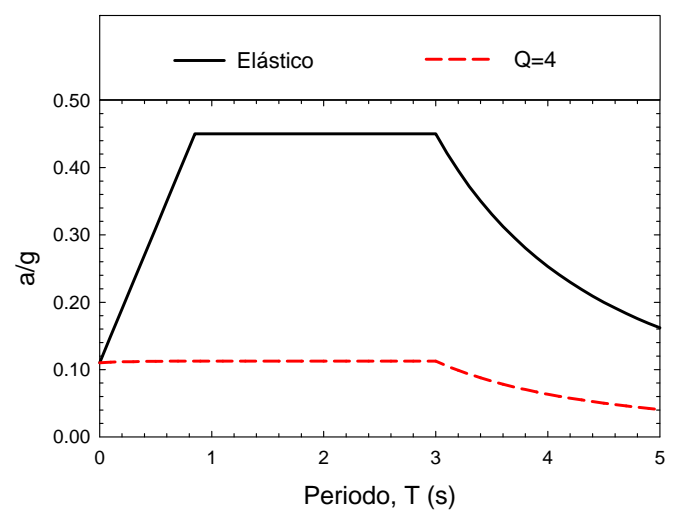

Figura 3. Espectros de diseño correspondientes a la zona III-b

\section{Descripción y consideraciones generales para el diseño de elementos de concreto y acero}

Es importante destacar que en el RCDF-04 y sus Normas Técnicas Complementarias no existen guías específicas para el diseño de marcos dúctiles de concreto reforzado con contravientos de acero. Al parecer, únicamente se hacen extrapolaciones de las guías dadas para el diseño de marcos dúctiles, lo cual no es necesariamente correcto, pues la presencia de contravientos afecta la distribución de elementos mecánicos en columnas y vigas, ya que se reducen los momentos flexionantes pero en cambio, aumentan las cargas axiales (Tena 2007), como se discute más adelante. En particular, la revisión de la integridad del nudo necesariamente tiene que hacerse de manera distinta por la presencia de los contravientos. Por esto, a continuación se presenta una descripción general de la metodología de diseño adoptada, la cual está basada en conceptos de diseño por capacidad.

\section{Criterios para el diseño de contravientos}

Para el diseño de los elementos de contraventeo, primeramente deben seleccionarse los balances de rigidez y resistencia entre las columnas y el sistema de contraventeo de cada entrepiso (figura 1). Con base en el porcentaje de resistencia a fuerza cortante seleccionado para el sistema de contraventeo, se determinan las secciones requeridas para satisfacer dicho requerimiento, así como los requerimientos de rigidez lateral.

Los elementos de contraventeo se diseñaron con base en las cargas axiales esperadas, tomando en cuenta las recomendaciones de diseño que para elementos a tensión y a compresión dictan las NTCEM04. Se buscó en cada caso que la sección propuesta fuese compacta, y en la mayoría de los modelos (excepto uno) se cumplieron las limitaciones en cuanto a relaciones de esbeltez $\left(k L / r<5.88 \sqrt{E} / F_{y}\right)$. En todos los casos se emplearon diagonales con sección cajón. Estos elementos se diseñaron tratando de 
evitar un diseño muy conservador en el que existan fuentes locales innecesarias de sobrerresistencia, pues son en teoría los elementos más débiles de este sistema estructural, si se desea diseñar intentando garantizar que el mecanismo último de falla sea congruente con el esperado (columna fuerte-viga débilcontraviento más débil).

\section{Criterios para el diseño de vigas}

El segundo grupo de elementos en diseñarse fueron las vigas, el siguiente elemento débil asociado a un mecanismo de falla dúctil. Primeramente, se determinan las fuerzas axiales actuantes en las vigas, tema que no abordan las NTCC-04 en el diseño de marcos dúctiles con contravientos.

En la figura 4 se ilustra esquemáticamente el procedimiento empleado para el cálculo de la carga axial actuante en las vigas correspondientes a las crujías centrales (no contraventeadas) y la carga actuando de izquierda a derecha. $P$ indica la carga axial actuante, $C$ y $T$ la compresión y tensión en los contravientos, respectivamente (se supuso que en los contravientos se desarrolla su capacidad total, considerando pandeo en compresión y fluencia en tensión).

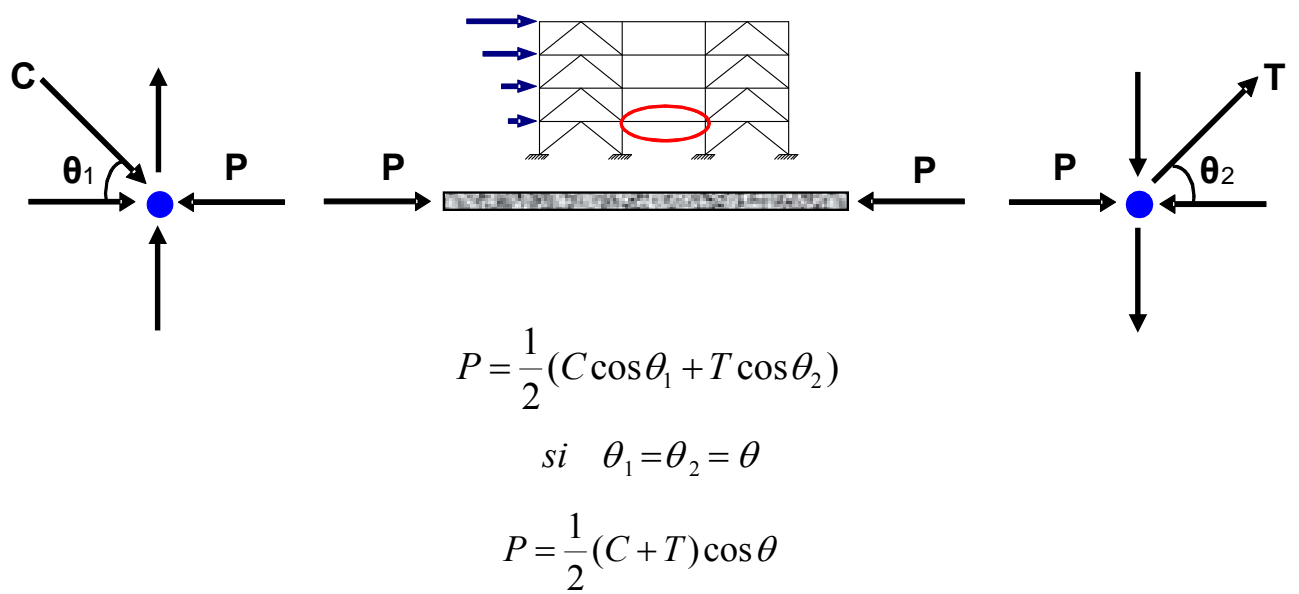

Figura 4. Determinación de la carga axial en vigas

Debido a que las NTCC-04 consideran un elemento trabajando a flexión a aquél que soporta cargas axiales menores de $A_{g} f_{c}^{\prime} / 10$, en el caso en que la carga axial calculada en las vigas exceda este límite, los elementos fueron diseñados como elementos en flexocompresión, en caso contrario, las vigas se diseñaron como elementos sujetos a flexión.

Es importante hacer notar que las cuantías de refuerzo mínimas y máximas se respetaron de acuerdo al tipo de diseño seguido en cada elemento, es decir, en los casos en que las vigas se diseñaron por flexocompresión, las cuantías de refuerzo adoptadas fueron las especificadas para este tipo de elementos en las NTCC-04.

Con la finalidad de evitar fallas prematuras por fuerza cortante, la fuerza cortante de diseño se determinó del equilibrio del miembro entre caras de apoyos; suponiendo que en los extremos actúan momentos del mismo sentido. Estos momentos representan una aproximación de la resistencia a flexión y fueron valuados con las propiedades del elemento en esas secciones, con factor de resistencia unitario, y con el esfuerzo en el acero de tensión igual a $1.25 F_{y}$. A lo largo del miembro se consideraron las cargas 
factorizadas (figura 5), una aproximación basada en conceptos de diseño por capacidad que consideran las NTCC-04 así como otros códigos de diseño internacional (por ejemplo, ACI-318).

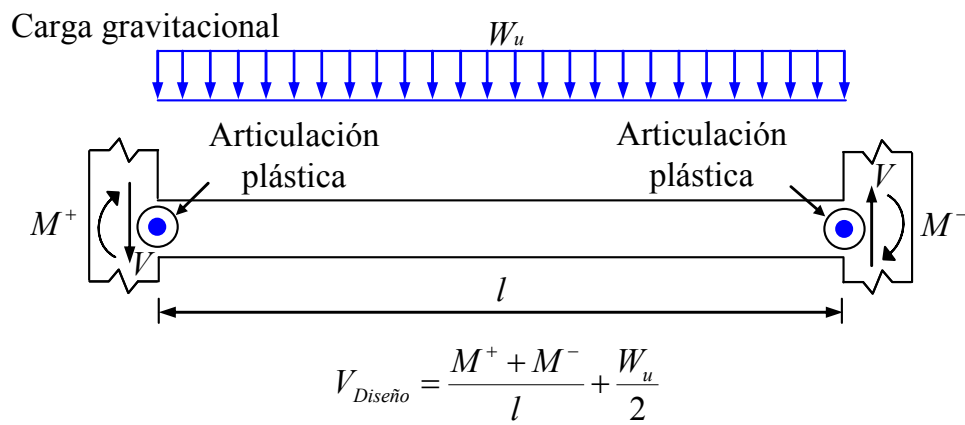

Figura 5. Determinación de la fuerza cortante de diseño en vigas (adaptada de las NTCC-04 2004)

\section{Criterios para el diseño de columnas}

Para el diseño de las columnas se siguieron las recomendaciones para marcos dúctiles de las NTCC04, empleando en todos los casos el método riguroso (procedimiento general), es decir, basado en un diseño por capacidad. Se presta principal atención a factores tales como la carga axial máxima permisible, así como a la forma en que ésta se estima.

Para el cálculo de la carga axial de diseño en las columnas, se consideraron los dos casos siguientes:

(a) La carga axial calculada del análisis estructural para las distintas combinaciones de carga.

(b) La carga gravitacional que debe tomar la columna más la componente vertical de fuerza que los contravientos pueden desarrollar y le transmiten a las columnas, ya fuese en compresión o en tensión, es decir, se toma un criterio de diseño por capacidad. Esta componente de fuerza es de mayor importancia en la medida en que la rigidez de los contravientos aumenta (Godínez 2010).

La carga axial de diseño en columnas correspondió a la máxima obtenida con base en los dos criterios previos.

Como lo proponen Luna y Tena (2002) y Tena et al. (2008), es conveniente hacer notar que la disposición de las NTCC-04 que limita el área de la sección transversal a que sea al menos igual a $P_{u} / 0.5 f_{c}^{\prime}$ debería aparecer como una restricción de la carga axial de diseño, más que una limitación de tipo geométrico, ya que en la práctica es común el empleo de programas comerciales de análisis estructural como el ETABS, SAP-2000, RC Buildings y STAAD-III, que contienen criterios de diseño de estructuras de concreto basados en el reglamento ACI-318, en el que no se incluye dicha restricción geométrica, lo cual marca una diferencia importante en el procedimiento de diseño respecto a las NTCC04, por lo que esta disposición geométrica pasa prácticamente inadvertida en la práctica de diseño estructural en México.

La condición anterior, que se ilustra en la figura $6 c$, fue cuidadosamente atendida en cada uno de los diseños de elementos en flexocompresión, mediante la construcción de los diagramas de interacción de cada elemento a diseñar. Se observa de la figura $6 \mathrm{c}$ que la carga axial de diseño permisible no puede 
encontrarse dentro de la zona achurada $\left(P_{\max }<0.5 A_{g} f_{c}^{\prime}\right)$. Lo anterior se hace con la finalidad de garantizar una capacidad de rotación razonable en zonas de las columnas donde pueden formarse articulaciones plásticas, pues como es bien sabido, la capacidad de rotación de un elemento decrece conforme se incrementa la carga axial (Park y Paulay 1978). Este aspecto, como se comentó, al tratarse como un mero requisito geométrico suele dejarse de lado, lo cual pudiese no ocurrir si se considerara la opción de ser tratado como un requisito que afecta directamente a un elemento mecánico.

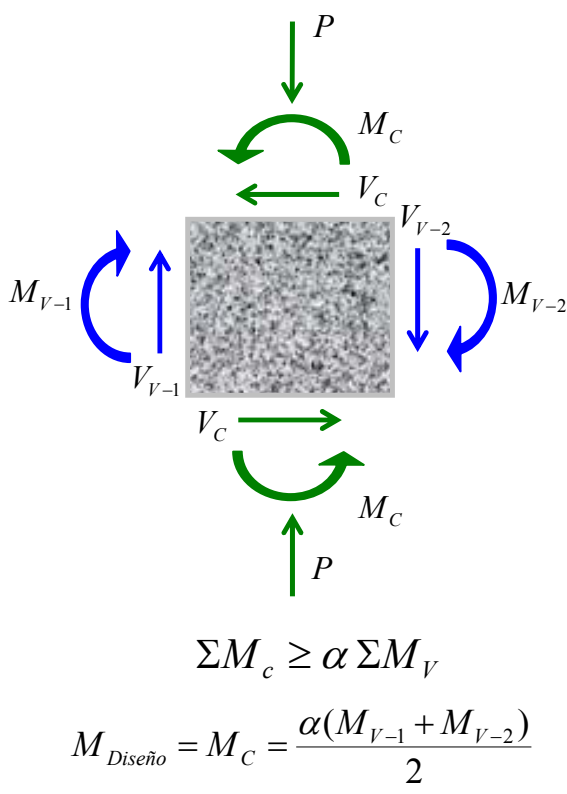

a)

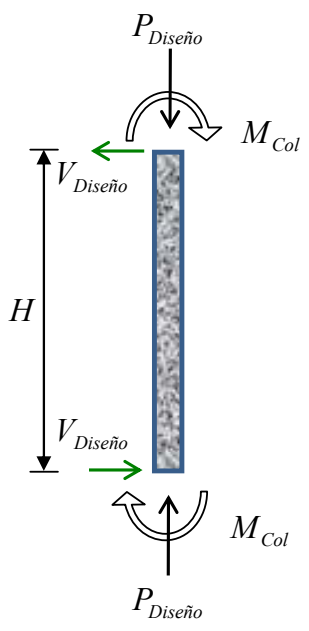

$V_{\text {Diseño }}=\frac{2 M_{C o l}}{H}$

b)

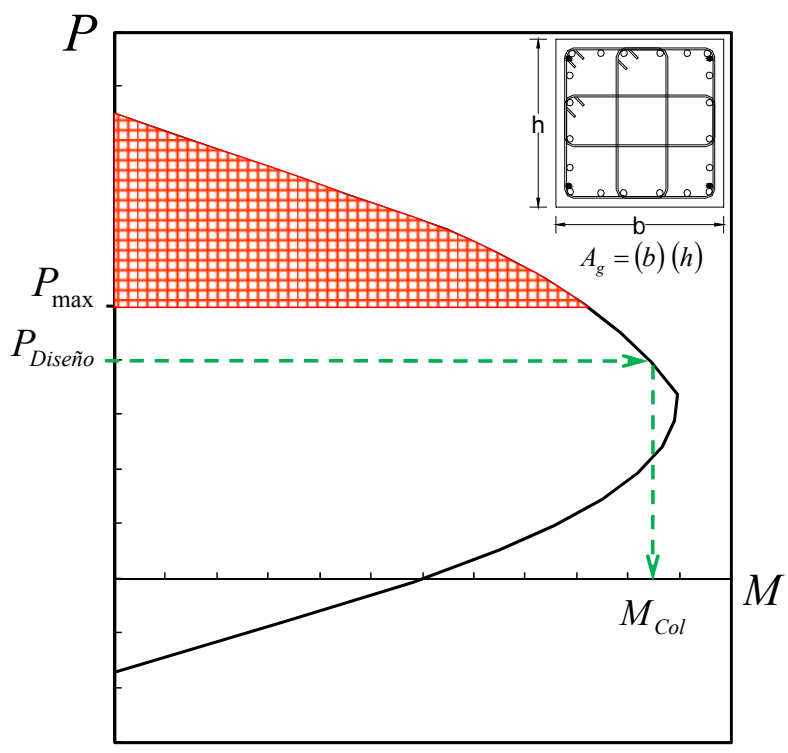

c) $P_{\max } \leq 0.5 f_{c}^{\prime} A_{g}$

Figura 6. Estimación de: a) Momentos de diseño en columnas, b) Fuerza cortante de diseño en columnas y, c) Carga axial máxima permisible y procedimiento para el cálculo de momentos flexionantes para la estimación de la fuerza cortante de diseño en columnas 
El momento de diseño de las columnas $\left(M_{\text {Diseño }}\right)$ se determinó con base en el equilibrio de los nodos a los que concurre cada elemento a diseñar (figura 6a). Para esto, se consideró la resistencia a flexión mínima requerida en las columnas de un nudo para asegurar un mecanismo de columna fuerte-viga débil, tal y como se establece en diversos reglamentos internacionales como el ACI-318 (ACI-318-08 2008), UBC (UBC-97 1997), y las NTCC-04 (NTCC-04 2004). Por tanto, para cada caso se revisó el cumplimiento de la ecuación 1.

$\sum M_{C}=\alpha \sum M_{V}$

donde:

$\sum M_{C}=$ Suma de los momentos, al centro de la junta, correspondiente a la resistencia de diseño a flexión de las columnas que forman el marco en dicha junta.

$\sum M_{V}=$ Suma de momentos al centro de la junta, correspondiente a las resistencias de diseño a flexión de las vigas que forman el marco en dicha junta.

$\alpha=$ Factor que amplifica la suma de momentos de las vigas, que para el caso de las NTCC-04 tiene un valor de 1.5 (el ACI-318 especifica un valor de $\alpha=1.2$ ).

Para la revisión de la resistencia a flexión mínima de las columnas en el nudo, a falta de lineamientos específicos que indiquen cómo hacer esta revisión para marcos contraventeados, se emplea la propuesta estipulada en el apartado 7.3.2 de las NTCC-04 para marcos no contraventeados. Sin embargo, cabe aclarar que en dicho apartado no se indica qué carga axial debe considerarse para realizar la revisión, ni para el caso de marcos momento-resistentes y mucho menos para un sistema mixto con contravientos, como los estudiados en esta investigación.

La carga axial empleada para realizar esta revisión se estimó como aquella carga axial que condujera a la menor resistencia a flexión, lo cual se calculó mediante: (a) la suma algebraica de la carga axial obtenida del análisis estructural para las diferentes combinaciones de carga, (b) la carga axial por carga vertical exclusivamente y, (c) la componente de fuerza que los contravientos pueden transmitirle a la columna cuando éstos desarrollan su capacidad a tensión o compresión, sumándole a ésta la carga axial actuante que se espera tome la columna por cargas gravitacionales.

Dadas las consideraciones hechas, algunas columnas pudiesen llegar a tener cargas de tensión importantes, lo cual debe considerarse en su diseño. Debido a que la única manera de dar resistencia a tensión es mediante el aumento del acero longitudinal, ocasionando un aumento en el momento resistente de la columna, debe tenerse en cuenta que un refuerzo longitudinal excesivo puede afectar directamente al cortante de diseño, el cual se calcula del equilibrio de la sección en su altura libre.

Respecto al diseño por fuerza cortante, para evitar fallas prematuras por este efecto, congruente a lo previamente realizado, se empleó un criterio de diseño por capacidad, es decir, la fuerza cortante de diseño se calculó del equilibrio del elemento en su altura libre, suponiendo que en sus extremos actúan momentos flexionantes del mismo sentido, numéricamente iguales a los momentos que representan una aproximación a la resistencia real a flexión de esas secciones, con factor de reducción por resistencia igual a uno (figura 6b). Los momentos flexionantes $\left(M_{c o l}\right)$ empleados en el cálculo de la fuerza cortante de diseño se determinaron a partir de los diagramas de interacción de cada elemento, identificando el momento 
flexionante asociado a la carga axial de diseño $\left(P_{\text {Diseño }}\right)$, es decir, se emplea la carga axial de diseño que conduce al mayor momento flexionante resistente (figura $6 \mathrm{c}$ ).

\section{Criterios de diseño/revisión de los nudos}

Los nudos fueron diseñados para resistir las demandas de fuerza cortante con base en: (a) el número de caras confinadas (a partir de lo cual se determinó la resistencia del concreto a fuerza cortante) y, (b) las fuerzas cortantes actuantes calculadas con base en el refuerzo por flexión de las vigas que concurren a los nudos, así como el refuerzo de la losa considerado en un ancho equivalente, tomando en cuenta que todo el refuerzo por flexión es capaz de alcanzar su esfuerzo de fluencia el cual se tomó con valor de $1.25 F_{y}$, como es práctica común en el diseño de conexiones en marcos dúctiles. Es importante mencionar que, adicional a la demanda de fuerza cortante calculada con base en el refuerzo longitudinal de vigas y losa, se consideró la componente de fuerza horizontal transmitida a la conexión por parte de las diagonales de contraventeo por la proyección de la carga axial que se desarrolla en dichos elementos.

El procedimiento descrito es una adaptación simple de lo actualmente propuesto en las NTCC-04 y otros códigos internacionales (por ejemplo ACI-318) para el caso de marcos dúctiles momento-resistentes. Sin embargo, es importante hacer notar que, en la mayoría de los códigos internacionales existen algunas limitantes para el diseño y revisión de nudos, a los que además de vigas y columnas, concurren elementos adicionales como los son las diagonales de contraventeo, por lo que este tema debe estudiarse con mayor detalle, lo cual daría bases para definir si la adaptación realizada en este estudio es adecuada o se requieren realizar cambios mayores en la metodología de diseño considerada.

Los lineamientos de las NTCC-04 no consideran la posibilidad de tener nudos a los cuales llegan contravientos y, por ello, no existen guías específicas de cómo revisarlos y diseñarlos. No se establece cómo revisar un nudo donde se reducen notablemente los giros (en el intervalo elástico por lo menos) $\mathrm{y}$, por ello, los momentos flexionantes y las respectivas fuerzas cortantes que se transmitirían al nudo por parte de vigas y columnas. Respecto a este punto, no existe evidencia analítica o experimental que indique como dichos giros se incrementan en el intervalo inelástico al presentarse el pandeo de los contravientos o en su caso fluencias en las vigas. Asimismo, no se dan guías de cómo revisar la transmisión de las fuerzas axiales de los contravientos al nudo, las que dependen en mucho del esquema de conexión que se quiera utilizar, si se usa una conexión donde se tiende a concentrar la fuerza axial, o si se elige un esquema de conexión donde se distribuye la fuerza del contraviento de manera más uniforme en la vecindad del nudo, a través de vigas y columnas. Este no es un tema menor que no está debidamente cubierto en las NTCC04 , y es una asignatura pendiente en este estudio y deberá abordarse en investigaciones futuras.

De lo anterior, resulta evidente la necesidad de realizar programas experimentales enfocados a la determinación de la influencia que los contravientos metálicos tienen en el desempeño de estructuras nuevas de concreto reforzado, así como el comportamiento y diseño de las conexiones con base en la configuración seleccionada.

\section{Generalidades de los diseños}

En los diseños realizados, la sección de columnas se varió de acuerdo al número de niveles del marco. En el caso de los marcos de cuatro niveles, la sección de columnas permaneció uniforme en altura, al igual que las vigas y contravientos. Para los marcos de 8 a 24 niveles, la variación de secciones de columnas y vigas se realizó cada cuatro niveles, alternando la variación de las secciones en el caso de los contravientos, los cuales para los modelos de 4 a 16 niveles variaron de espesor cada tres niveles, manteniendo su sección transversal, en tanto que para los modelos de 20 y 24 niveles, la variación del 
espesor de la sección quedó determinada de tal manera que las secciones propuestas estuviesen diseñadas lo más justas posibles.

Lo anterior obedece a tratar de evitar crear planos de debilidad en algún entrepiso, pues se observó por medio de los análisis estáticos no lineales, que la práctica de variar en el mismo entrepiso las secciones de vigas, columnas y contravientos conducía a la posible generación de pisos débiles, ocasionando fallas no deseadas y reduciendo significativamente la ductilidad del sistema.

Para el dimensionamiento de las columnas rigió siempre el criterio de resistencia, pues por tratarse de un sistema contraventeado, el cumplimiento de las distorsiones de entrepiso especificadas en las NTCS-04 para el estado límite de prevención de colapso no presentó dificultades, en especial para los modelos de baja y mediana altura. Para el cálculo del refuerzo transversal, prácticamente en todos los casos rigió el criterio de resistencia por fuerza cortante y no el de confinamiento. Para el dimensionamiento de vigas, al igual que en columnas, rigió el criterio de resistencia.

Los armados de vigas y columnas en varios casos, únicamente debieron cumplir con los requisitos mínimos, esto debido a que se tienen secciones más robustas de lo requerido por resistencia. Por el mismo motivo, para los marcos de cuatro niveles, en especial al estudiar el caso en que el $75 \%$ de la resistencia a fuerza cortante es aportada por los contravientos (no contemplado en las NTCS-04 para comportamiento dúctil), se presentan niveles de sobrerresistencia bastante elevados.

En todos los casos los contravientos son secciones cajón de acero A-36, como es práctica común tanto en el caso de proyectos de refuerzo estructural (concreto o acero), como para el caso de diseños nuevos de estructuras metálicas.

Para identificar los distintos diseños, se utilizó la siguiente nomenclatura general para los modelos: $m N d p p$, donde la $m$ indica que se trata de un marco, $N$ indica el número de niveles, $d$ indica la dirección de análisis $(X \circ Y)$ conforme a la planta de los modelos (figura 2a), y los últimos dos caracteres $(p p)$ indican el porcentaje de fuerza cortante que toman las columnas del marco. Por ejemplo, el modelo m12y75, identifica el diseño de un marco de doce niveles en la dirección $Y$ de la planta de la figura 2a, donde las columnas aportan aproximadamente el $75 \%$ de la resistencia a fuerza cortante en el entrepiso. Así, se diseñaron los siguientes marcos: $\mathrm{m} 4 \mathrm{y} 25, \mathrm{~m} 4 \mathrm{y} 50, \mathrm{~m} 4 \mathrm{y} 75, \mathrm{~m} 4 \mathrm{x} 25, \mathrm{~m} 4 \mathrm{x} 50, \mathrm{~m} 4 \mathrm{x} 75, \mathrm{~m} 8 \mathrm{y} 25, \mathrm{~m} 8 \mathrm{y} 50, \mathrm{~m} 8 \mathrm{y} 75$, $\mathrm{m} 8 \mathrm{x} 25, \mathrm{~m} 8 \mathrm{x} 50, \mathrm{~m} 8 \mathrm{x} 75, \mathrm{~m} 12 \mathrm{y} 25, \mathrm{~m} 12 \mathrm{y} 50, \mathrm{~m} 12 \mathrm{y} 75, \mathrm{~m} 12 \mathrm{x} 25, \mathrm{~m} 12 \mathrm{x} 50, \mathrm{~m} 12 \mathrm{x} 75, \mathrm{~m} 16 \mathrm{y} 25, \mathrm{~m} 16 \mathrm{y} 50$, m16y75, m16x25, m16x50, m16x75, m20y25, m20y50, m20y75, m20x25, m20x50, m20x75, m24y25, $\mathrm{m} 24 \mathrm{y} 50, \mathrm{~m} 24 \mathrm{y} 75, \mathrm{~m} 24 \mathrm{x} 25, \mathrm{~m} 24 \times 50$ y $\mathrm{m} 24 \times 75$ (tabla 1). En la tabla 1 se resumen para cada modelo, el caso de estudio, así como las propiedades dinámicas del mismo y la masa asociada al primer modo de vibrar. Los diseños se reportan con detalle en Godínez (2010).

\section{CONSIDERACIONES PARA LOS ANÁLISIS NO LINEALES}

Se realizaron análisis no lineales ante cargas monótonas crecientes ("pushover"), para los cuales se empleó el programa DRAIN-2DX (Prakash et al. 1992). Por simplicidad, en todos los análisis se empleó el vector de cargas correspondiente al primer modo de vibración. Lo anterior se realizó para contar con un marco de comparación, tomando en cuenta que: (a) los modelos en estudio están en el intervalo de los cuatro a los 24 niveles, (b) la masa modal asociada al modo fundamental de vibración es, en general, superior al 70\% en el caso de los modelos con comportamiento dúctil (tabla 1) y, (c) los sistemas estudiados tienen una rigidez lateral importante, por lo que el efecto de los modos superiores no tiene impacto significativo en la respuesta estructural, tal y como se comenta con detalle en Godínez (2010), en donde se comparan los resultados de análisis no lineales ante carga monótona creciente basados en 
distribuciones de cargas laterales asociadas al modo fundamental de vibración respecto a los obtenidos al considerar la contribución en la respuesta de un mayor número de modos de vibrar ("modal pushover"), procediendo conforme lo descrito en la literatura especializada (Chopra y Goel 2001 y 2002, Goel y Chopra 2004).

Tabla 1. Casos de estudio y características dinámicas

\begin{tabular}{|c|c|c|c|c|c|c|c|c|c|}
\hline Modelo & $\begin{array}{l}\text { Caso de } \\
\text { estudio }\end{array}$ & $H / L$ & $\begin{array}{c}T \\
(\mathrm{seg})\end{array}$ & $\begin{array}{c}\text { Masa } \\
\text { modal } \\
(\%)\end{array}$ & Modelo & $\begin{array}{l}\text { Caso de } \\
\text { estudio }\end{array}$ & $H / L$ & $\begin{array}{c}T \\
\text { (seg) }\end{array}$ & $\begin{array}{c}\text { Masa } \\
\text { modal } \\
(\%)\end{array}$ \\
\hline $\mathrm{m} 4 \times 25$ & I & 0.43 & 0.231 & 86.42 & $\mathrm{~m} 16 \times 25$ & I & 1.70 & 1.147 & 70.74 \\
\hline $\mathrm{m} 4 \times 50$ & II & 0.43 & 0.309 & 85.66 & $\mathrm{~m} 16 \times 50$ & II & 1.70 & 1.164 & 72.18 \\
\hline $\mathrm{m} 4 \times 75$ & III & 0.43 & 0.310 & 83.88 & $\mathrm{~m} 16 \times 75$ & III & 1.70 & 1.102 & 72.99 \\
\hline m4y25 & I & 0.65 & 0.203 & 85.93 & m16y 25 & I & 2.59 & 1.139 & 70.74 \\
\hline m4y50 & II & 0.65 & 0.282 & 85.73 & m16y50 & II & 2.59 & 1.105 & 71.46 \\
\hline $\mathrm{m} 4 \mathrm{y} 75$ & III & 0.65 & 0.277 & 84.37 & $\mathrm{~m} 16 \mathrm{y} 75$ & III & 2.59 & 1.067 & 73.10 \\
\hline $\mathrm{m} 8 \mathrm{x} 25$ & I & 0.85 & 0.514 & 77.92 & $\mathrm{~m} 20 \times 25$ & I & 2.13 & 1.396 & 68.44 \\
\hline $\mathrm{m} 8 \mathrm{x} 50$ & II & 0.85 & 0.604 & 79.00 & $\mathrm{~m} 20 \times 50$ & II & 2.13 & 1.386 & 73.00 \\
\hline $\mathrm{m} 8 \times 75$ & III & 0.85 & 0.543 & 78.38 & $\mathrm{~m} 20 \times 75$ & III & 2.13 & 1.300 & 72.59 \\
\hline m8y25 & I & 1.30 & 0.525 & 77.64 & $\mathrm{~m} 20 \mathrm{y} 25$ & I & 3.24 & 1.409 & 68.69 \\
\hline m8y50 & II & 1.30 & 0.570 & 78.23 & $\mathrm{~m} 20 \mathrm{y} 50$ & II & 3.24 & 1.340 & 71.49 \\
\hline m8y75 & III & 1.30 & 0.509 & 78.22 & $\mathrm{~m} 20 \mathrm{y} 75$ & III & 3.24 & 1.281 & 72.55 \\
\hline $\mathrm{m} 12 \times 25$ & I & 1.28 & 0.864 & 73.79 & $\mathrm{~m} 24 \times 25$ & I & 2.55 & 1.774 & 68.03 \\
\hline $\mathrm{m} 12 \times 50$ & II & 1.28 & 0.880 & 74.85 & $\mathrm{~m} 24 \times 50$ & II & 2.55 & 1.611 & 72.75 \\
\hline $\mathrm{m} 12 \times 75$ & III & 1.28 & 0.786 & 75.54 & $\mathrm{~m} 24 \times 75$ & III & 2.55 & 1.573 & 72.43 \\
\hline $\mathrm{m} 12 \mathrm{y} 25$ & I & 1.94 & 0.810 & 73.08 & $\mathrm{~m} 24 \mathrm{y} 25$ & I & 3.89 & 1.767 & 67.29 \\
\hline $\mathrm{m} 12 \mathrm{y} 50$ & II & 1.94 & 0.822 & 74.41 & $\mathrm{~m} 24 \mathrm{y} 50$ & II & 3.89 & 1.718 & 70.97 \\
\hline $\mathrm{m} 12 \mathrm{y} 75$ & III & 1.94 & 0.743 & 74.95 & $\mathrm{~m} 24 \mathrm{y} 75$ & III & 3.89 & 1.644 & 71.01 \\
\hline
\end{tabular}

Se incluyen en todos los casos los efectos P- $\Delta$ en columnas y diagonales y se ignora la interacción suelo estructura. El efecto de la interacción suelo estructura no se considera en este estudio para evitar introducir mayor cantidad de variables que compliquen la interpretación de los resultados.

Todos los marcos perimetrales estudiados $(4,8,12,16,20$ y 24 niveles) guardan la misma configuración (figura 2b). En este estudio se identifican dos grupos de resultados: (1) los asociados a aquéllos obtenidos con base en resistencias y propiedades nominales de los elementos y, (2) los asociados a aquéllos en que se consideran fuentes adicionales de resistencia (sobrerresistencia). Los criterios para la determinación de resistencias en ambos casos se describen con detalle en Godínez y Tena (2007) y Godínez (2010).

\section{RESULTADOS DE LOS ANÁLISIS NO LINEALES}

Los principales resultados obtenidos de los análisis no lineales estáticos son: (1) curvas normalizadas cortante-distorsión para cada uno de los entrepisos $\left(V / W_{T} v s \Delta\right)$, así como globales (cortante basal vs distorsión de azotea), (2) mapeo de rotaciones plásticas acumuladas asociadas al colapso teórico de la estructura. 
La distorsión última se limitó en función de la rotación máxima que los elementos estructurales son capaces de desarrollar, así como de las longitudes de pandeo calculadas para los contravientos (Godínez 2010).

De las curvas cortante-distorsión tanto a nivel entrepiso como a nivel global se obtuvo la siguiente información: (a) factores de reducción por sobrerresistencia, (b) factores de reducción de fuerzas sísmicas, (c) capacidades de deformación inelástica globales y de entrepiso, (d) distorsiones de fluencia de entrepiso equivalentes, (e) distorsiones máximas. Estos parámetros son importantes para el diseño de un sistema estructural específico y, fueron calculados a partir de una curva bilineal idealizada de la curva cortantedistorsión real (figura 7), conforme a lo especificado en la literatura (Newmark y Hall 1982, FEMA-273 1997).

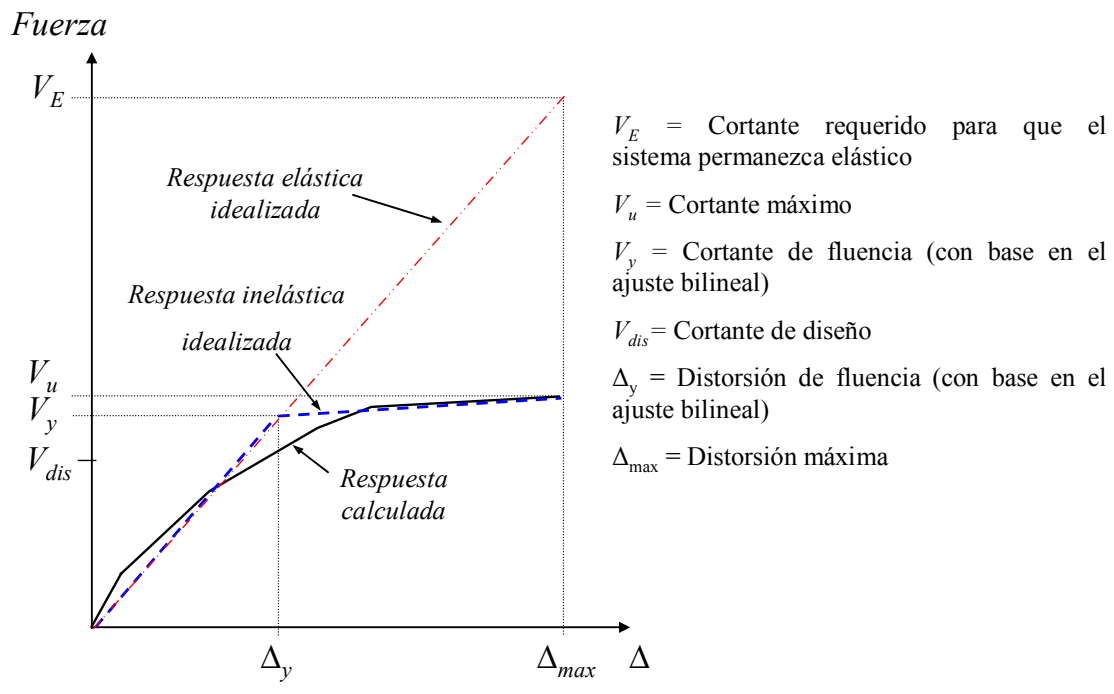

Figura 7. Idealización bilineal de las curvas cortante-distorsión

\section{Envolventes de distorsión de entrepiso máximas}

La distorsión de entrepiso de cualquier edificio con base en marcos que ha sido diseñado de manera rigurosa, tomando en cuenta los grados de libertad de traslación, de rotación y de deformación axial, y que además incluye los efectos de segundo orden o P- $\Delta$, se debe calcular también rigurosamente tomando en cuenta: (1) la distorsión angular debida a la diferencia de los desplazamientos laterales de niveles contiguos divididos por la altura, también conocida como la distorsión por cortante o "componente horizontal" de la distorsión y, (2) la distorsión debida a la flexión general del marco en la dirección de análisis, calculada como el ángulo debido a la diferencia entre la extensión y el acortamiento de las columnas extremas del marco dividida entre la distancia existente entre ambas columnas. A esta distorsión también se le conoce como "componente vertical" de la distorsión. Por ello, en este trabajo las distorsiones de entrepiso reportadas de la figura 9 en adelante toman en cuenta esta distorsión total: la suma de la distorsión por cortante más la debida a la flexión general de los marcos.

Cabe señalar, sin embargo, que es muy común que en algunos casos por facilidad, tanto en la academia como en la práctica profesional se calcule y reporte exclusivamente la distorsión por cortante 
(componente horizontal), dado que es la más simple de calcular en cualquier software, además de ser normalmente la dominante.

Con la finalidad de discernir qué tanto se pierde o no al despreciar o incluir la distorsión por flexión general ("componente vertical"), se evaluó para cada marco en estudio su impacto relativo, como se reporta con detalle en Godínez (2010). Con fines ilustrativos, en la figura 8 se presentan las envolventes de distorsiones de entrepiso máximas de entrepiso de los modelos de ocho, 16 y 24 niveles cuando se consideran sobrerresistencias y: (a) sólo se considera la distorsión por cortante ("componente horizontal", línea con rayas), (b) sólo se considera la distorsión por flexión general ("componente vertical", línea con raya y puntos) y, (c) se considera la distorsión total: por cortante más flexión general ("ambas componentes", línea continua). De las gráficas de la figura 8 se confirma que, como es bien sabido, la importancia de la distorsión por flexión (componente vertical) se incrementa con la altura y no menos importante, su impacto crece a medida que los contravientos tienen un mayor aporte a la rigidez y resistencia (modelos $\mathrm{m} 8 \mathrm{x} 25, \mathrm{~m} 16 \mathrm{x} 25 \mathrm{y} \mathrm{m} 24 \mathrm{x} 25$ ) y disminuye a medida que los marcos tienen un mayor aporte en rigidez y resistencia (modelos $\mathrm{m} 8 \times 75, \mathrm{~m} 16 \mathrm{x} 75$ y $\mathrm{m} 24 \times 75$ ).

Dado que, como se comentará más adelante, los comportamientos dúctiles se obtuvieron para los modelos en los que los marcos toman al menos el 50\% del cortante (modelos m8x50, m16x50, m24x50, $\mathrm{m} 8 \mathrm{x} 75, \mathrm{~m} 16 \mathrm{x} 75$ y $\mathrm{m} 24 \mathrm{x} 75)$, y para estos casos existe una diferencia despreciable entre tomar ambas componentes de la distorsión y sólo tomar la componente horizontal (distorsión por cortante), ya que la distorsión máxima de flexión (componente vertical) es menor al $0.1 \%$ aun para los modelos de 24 niveles, los profesionales que acostumbran despreciar la componente por flexión pueden seguir analizando con confianza a estos sistemas para las alturas y los balances de resistencia comentados. Sin embargo, resulta muy claro también de observar la figura 8 que para marcos donde los contravientos tienen un aporte muy importante a la rigidez y resistencia global del sistema, esta componente ya no es tan despreciable a medida que aumenta la altura, obteniéndose una distorsión por flexión global cercana al $0.25 \%$ para los últimos niveles del modelo $\mathrm{m} 24 \times 25$, debido a que este sistema se axializa demasiado y funciona más como una armadura.

\section{Curvas cortante-distorsión}

Con fines de optimizar el espacio, se presentan en esta sección únicamente las curvas cortantedistorsión globales y de entrepiso de los modelos de 24 niveles (figura 9). Las curvas de cada modelo estudiado se reportan con detalle en Godínez (2010).

En las curvas cortante-distorsión se muestran por separado la contribución de cada componente (columnas y contravientos) al cortante resistente en cada entrepiso y a nivel global. Asimismo, se muestra la suma de los dos componentes, la cual representa la resistencia lateral total del marco contraventeado. Conforme a lo reportado por Maheri y Akbari (2003) y por Ghaffarzadeh y Maheri (2006), este procedimiento es adecuado para el cálculo de la resistencia lateral total del sistema dual.

Como se comentó previamente, en las curvas mostradas en la figura 9 y subsecuentes, para el cálculo de la distorsión (de entrepiso y globales) se consideró tanto la distorsión por cortante como la debida a flexión; es decir, en ningún caso se restó de la distorsión total el efecto debido a flexión.

Se observa de la figura 9 que el comportamiento que presentan las columnas y contravientos difiere entre sí conforme la estructura ingresa en mayor medida a su intervalo de comportamiento plástico. Para la mayoría de los modelos, posterior a la primera fluencia, el porcentaje de fuerza cortante que resisten los contravientos crece (pendiente positiva), en tanto que el de las columnas disminuye (pendiente negativa), el mismo efecto se observa para los modelos de menor altura (Godínez y Tena 2007, Godínez y Tena 
2010). El fenómeno mencionado tiende a ser menos evidente conforme la altura de los marcos decrece, así como al incrementarse la contribución de las columnas al cortante resistente de entrepiso.

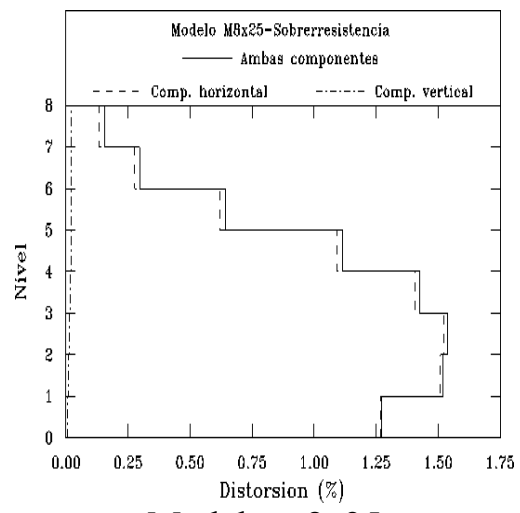

Modelo m8x25

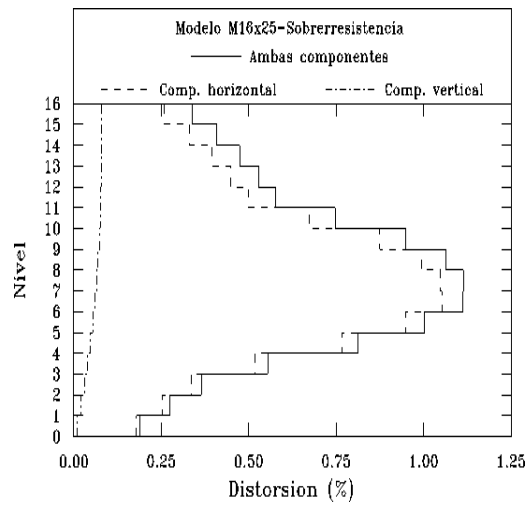

Modelo m16x25

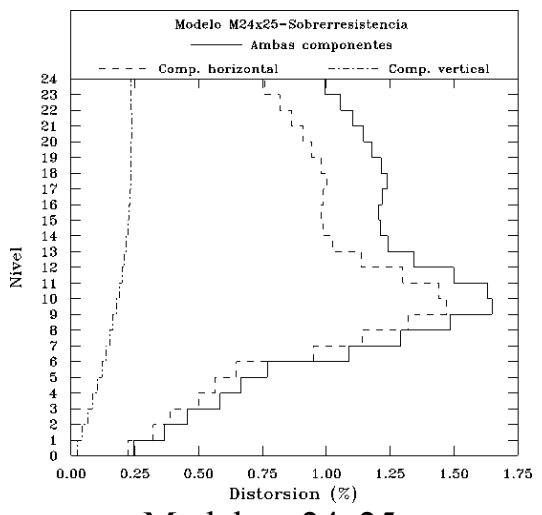

Modelo m24x25
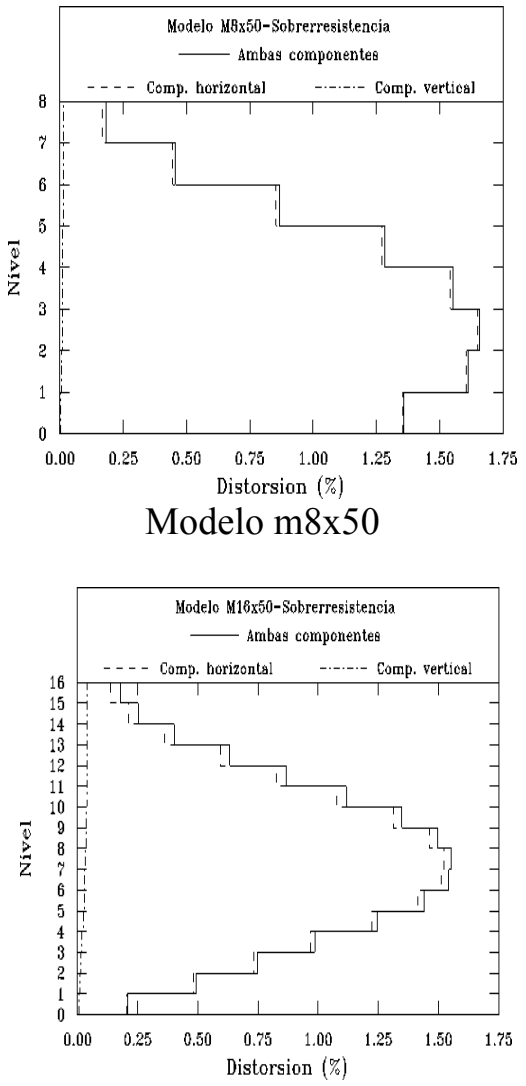

Modelo m16x50

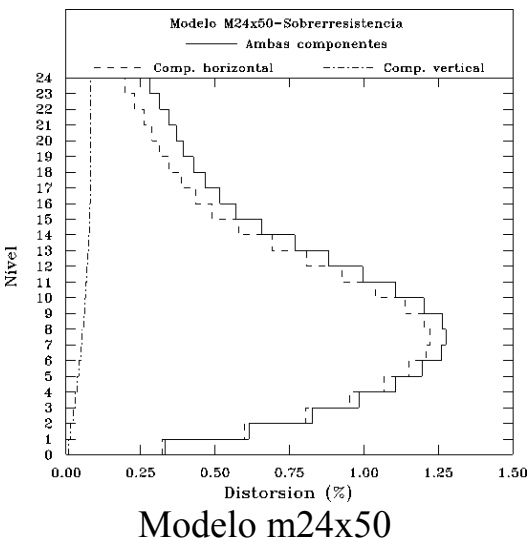

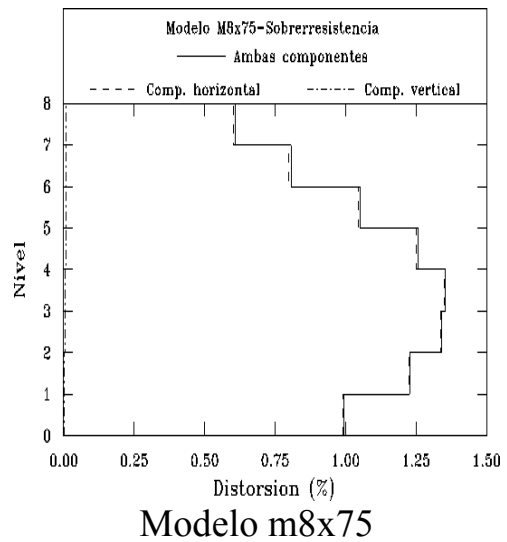

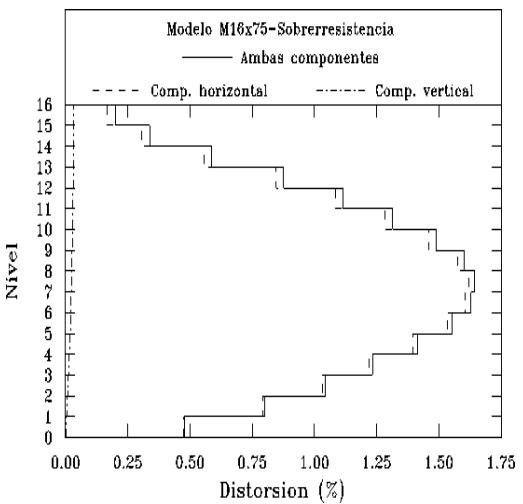

Modelo m16x75

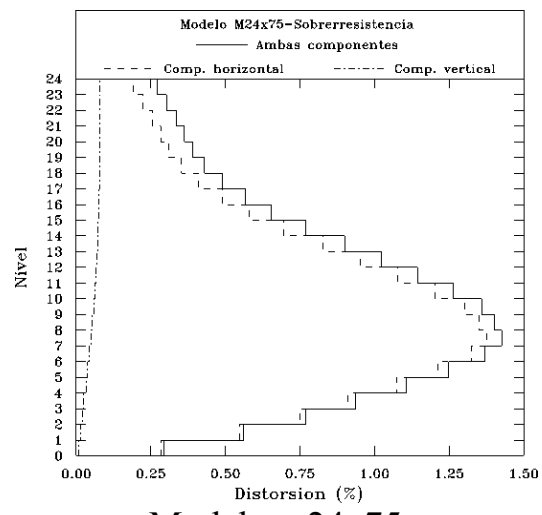

Modelo m24x75

Figura 8. Curvas envolventes de distorsiones de entrepiso de los modelos de 16, 20 y 24 niveles en dirección $\mathrm{X}$

Dado que el observar pendientes negativas en las curvas cortante-distorsión de las columnas de un entrepiso es un efecto poco común, se realizó un estudio minucioso de estos resultados como se reporta con detalle en Godínez (2010) y Godínez y Tena (2011). Se encontró que el efecto de la pendiente negativa en las curvas que definen la curva cortante-distorsión de las columnas de algunos entrepisos de 
niveles superiores se debe a lo siguiente: una vez que las diagonales de contraventeo que se encuentran en compresión en los entrepisos superiores comienzan a pandear, las rotaciones de los nodos adyacentes se incrementan de manera importante y con mayor proporción de lo que lo hacen los desplazamientos laterales. Dado que las fuerzas cortantes debidas a dichas rotaciones actúan en sentido contrario a las fuerzas cortantes asociadas al desplazamiento lateral, la suma o fuerza cortante resultante es negativa. Por lo tanto, a partir de dicho punto, estas curvas presentan pendiente negativa conforme el desplazamiento lateral se incrementa, en tanto la fuerza cortante decrece. La influencia de la carga vertical y los efectos P$\Delta$ pueden considerarse poco significativos para los modelos de baja altura; sin embargo, se observó que su impacto tiende a tener mayor relevancia conforme se incrementa la altura de los modelos (Godínez 2010, Godínez y Tena 2011).
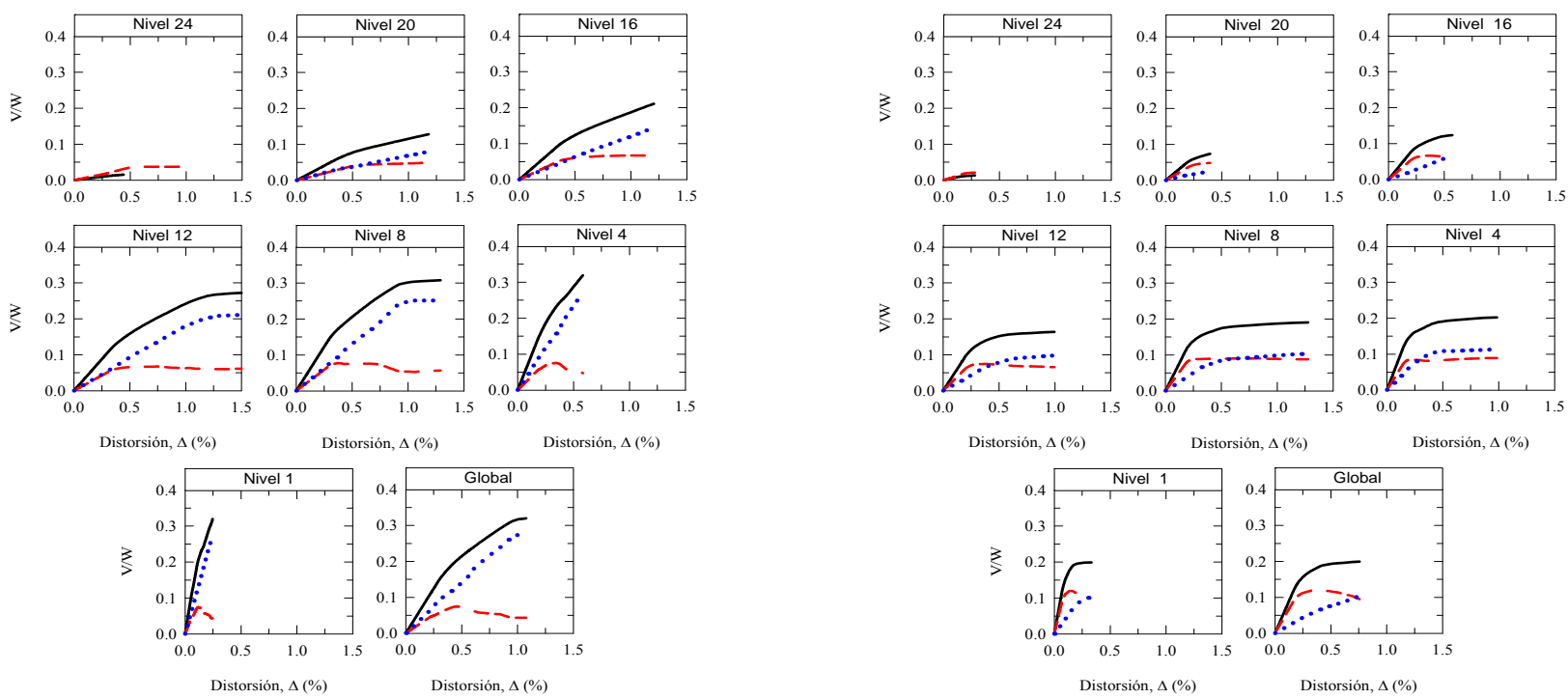

a) Modelo $m 24 \times 25$

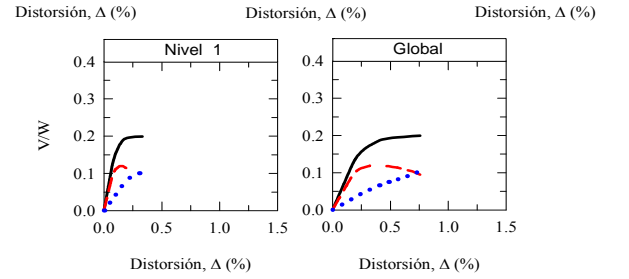

b) Modelo m24x50
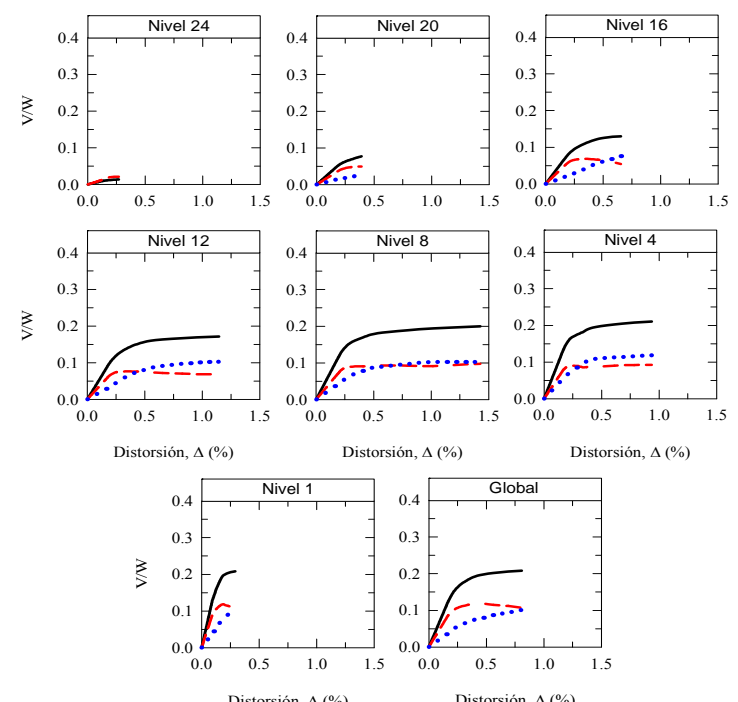

c) Modelo $m 24 x 75$

Total

Columnas

Contravientos

Figura 9. Curvas cortante-distorsión normalizadas para los modelos de 24 niveles 
En Godínez (2010) se ilustra con detalle el incremento de la carga axial conforme se incrementa la contribución de los contravientos al cortante resistente de entrepiso. Además, es importante considerar el cuidado que debe tenerse en la estimación de las cargas para el diseño de la cimentación, pues el omitir las cargas axiales provenientes de la componente vertical de fuerza de los contravientos, podría derivar en problemas de dimensionamiento importantes.

De la figura 9a se observa que en los modelos en que las columnas resisten cerca del $25 \%$ de la fuerza cortante total de entrepiso (modelo $\mathrm{m} 24 \times 25$ ) existe una menor demanda de comportamiento inelástico en los entrepisos superiores, permaneciendo prácticamente elásticos. Por otra parte, en los modelos en que las columnas resisten cerca del $75 \%$ de la fuerza cortante total de entrepiso (m24x 75 , figura 9c) se observa una mejor distribución del comportamiento inelástico en la altura del marco, lo cual es deseable para una mayor disipación de energía.

Del conjunto de modelos estudiados, se observó que en algunos casos, la respuesta global del sistema representada por la curva cortante basal $v s$ distorsión promedio (calculada con base en el desplazamiento de azotea) no es representativa del comportamiento de cada entrepiso, pues para algunos casos en los niveles superiores el comportamiento es prácticamente elástico hasta el último paso, en tanto que los pisos inferiores son capaces de desarrollar mayores distorsiones y niveles de cortante al ingresar a su intervalo de comportamiento plástico (figura 9).

Se observa que, en general, las mayores distorsiones se desarrollan en los niveles intermedios, precisamente en los niveles donde se hicieron cambios de sección en los modelos. Como se observará en secciones posteriores, es en dichos niveles donde los elementos estructurales experimentan las mayores rotaciones plásticas.

\section{Mapeos de rotaciones plásticas acumuladas}

Con la finalidad de identificar cuáles son los elementos en que se concentra el trabajo inelástico, así como para observar la secuencia de formación de articulaciones plásticas (vigas y columnas) y deformaciones plásticas (contravientos), lo cual brinda información valiosa para evaluar si los mecanismos de falla están asociados al esperado columna fuerte-viga débil-contraviento más débil, se realizaron mapeos de rotaciones plásticas en diferentes etapas del análisis.

En las figuras 10 y 11 se muestran los mapeos de rotaciones plásticas acumuladas para los modelos de ocho, 16, 20 y 24 niveles en dirección $X$ para el caso en que se consideran fuentes adicionales de sobrerresistencia. Los mapeos corresponden al paso asociado al colapso teórico de la estructura. Únicamente se presentan los resultados de los modelos en que las columnas resisten como mínimo el 50\% de la fuerza cortante de entrepiso. Lo anterior se debe, como se ha reportado y comentado previamente (Godínez y Tena 2008 y 2010, Godínez 2010), a que los modelos en que las columnas resisten un porcentaje menor al $50 \%$ de la fuerza cortante de entrepiso no presentan mecanismos de falla congruentes con el inicialmente planteado de columna fuerte-viga débil-contraviento más débil.

La magnitud de las rotaciones inelásticas en vigas y columnas se muestra mediante una escala de colores usando una marca circular; asimismo, las extensiones y acortamientos en diagonales se muestran mediante una segunda escala de colores empleando una marca en forma de óvalo.

Las capacidades de rotación teóricas de los elementos (vigas y columnas) se determinaron, tanto para los casos en que se consideran resistencias nominales como al considerar efectos de sobrerresistencia, mediante el cálculo de las curvas momento-curvatura empleando el programa Biax (Wallace y Moehle 
1989). Asimismo, la determinación de la magnitud del acortamiento que pueden sufrir las diagonales de contraventeo al momento del pandeo (longitudes de pandeo) se hizo con base en la propuesta de Kemp (1996), la cual se apoya en pruebas experimentales realizadas por varios investigadores a nivel mundial.

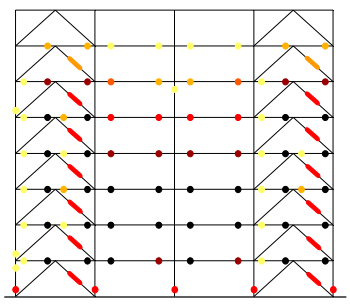

a) $\mathrm{m} 8 \times 50$

$0.00-0.0030$

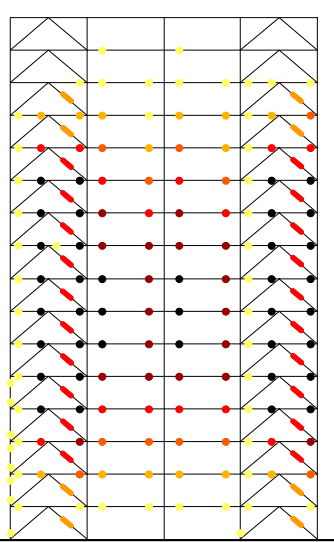

b) $\operatorname{m} 16 \times 50$

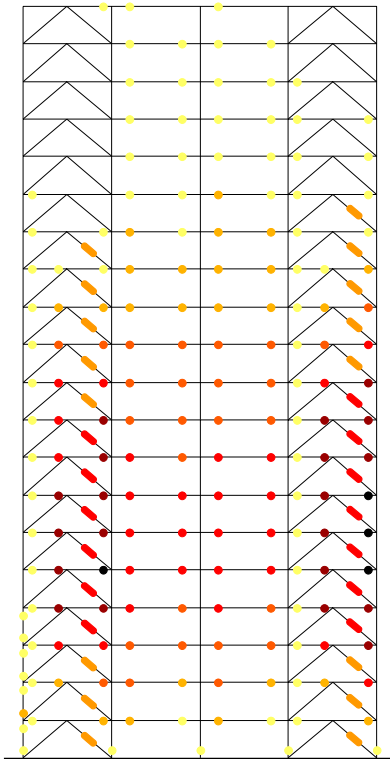

c) $\operatorname{m} 20 \times 50$

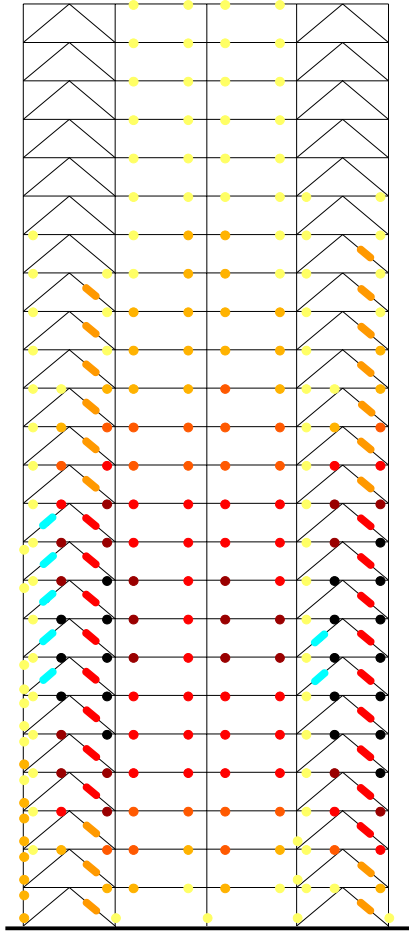

d) $\mathrm{m} 24 \times 50$
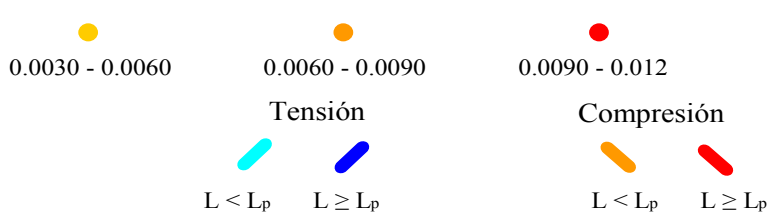

Figura 10. Rotaciones plásticas acumuladas de los modelos en que las columnas aportan aproximadamente el $50 \%$ de la resistencia a cortante

De los diseños realizados, se observó que para cumplir con el balance en que las columnas aportan únicamente el $25 \%$ de la fuerza cortante resistente total, las secciones de los contravientos deben ser muy robustas, lo que ocasiona que el mecanismo de falla columna fuerte-viga débil-contraviento más débil no se garantice. De hecho, la primera articulación plástica para estos modelos ocurre usualmente en una columna, y en ocasiones debido a la magnitud de la carga axial que se transmite de los contravientos a las columnas, pueden existir articulaciones plásticas en ambos extremos de las columnas, lo cual es muy poco deseable, pues pudiese presentarse un mecanismo asociado a un piso débil. Asimismo, la capacidad de deformación se reduce, lo cual es más evidente conforme se incrementa la altura de los modelos. Los resultados correspondientes a estos modelos se comentan con detalle en Godínez (2010).

Por lo anterior, es deseable realizar estudios detallados adicionales respecto a la distribución de la carga axial en modelos de diferentes alturas en que las columnas aportan únicamente el $25 \%$ de la resistencia a cortante de entrepiso, considerando que las estructuras se ubican en zonas diferentes a las 
empleadas en este estudio; pues sin duda, los niveles de aceleración para los cuales se diseña el sistema dual es una variable que puede impactar en el punto comentado.

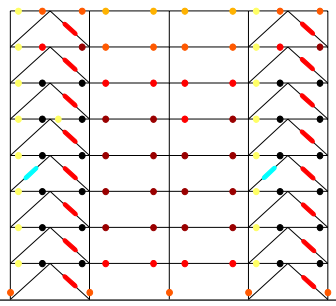

a) $\operatorname{m} 8 \times 75$

$0.00-0.0030$

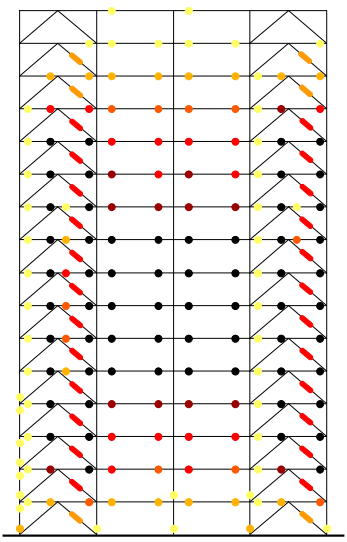

b) $\operatorname{m} 16 \times 75$

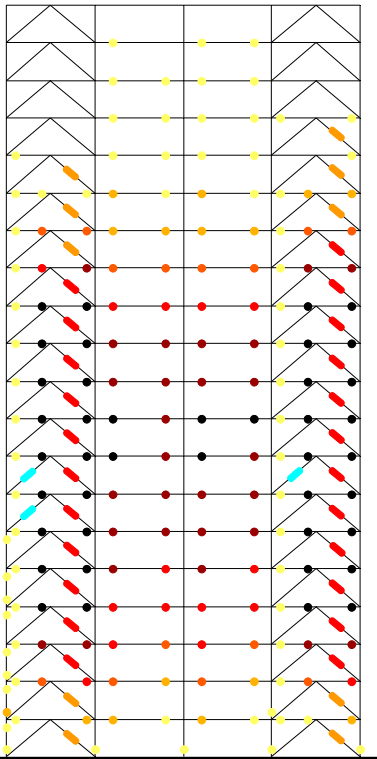

c) $\operatorname{m} 20 \times 75$

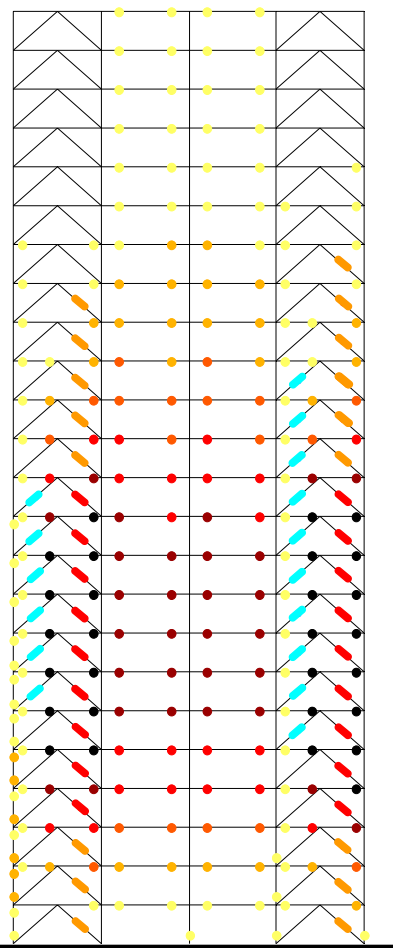

d) $\mathrm{m} 24 \times 75$
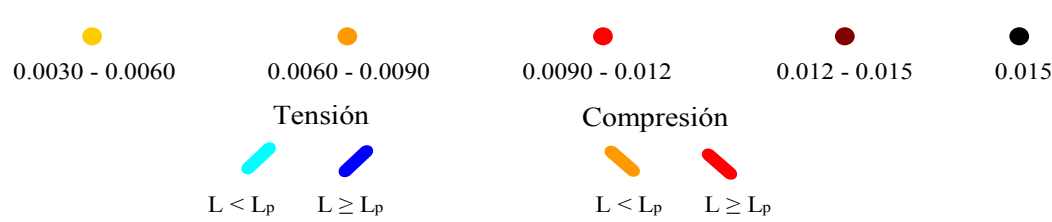

Figura 11. Rotaciones plásticas acumuladas de los modelos en que las columnas aportan aproximadamente el $75 \%$ de la resistencia a cortante

Para los modelos en que las columnas aportan aproximadamente el $50 \%$ de la fuerza cortante de entrepiso total (resistencia mínima estipulada en las NTCS-04 para comportamiento dúctil) y aquéllos en que aportan aproximadamente $75 \%$ de la fuerza cortante total (figuras 10 y 11 ) la distribución y magnitud de las rotaciones plásticas es similar. En estos casos la primera deformación inelástica ocurre siempre en un contraviento. Los mecanismos de colapso obtenidos para los modelos de baja y mediana altura (cuatro a 16 niveles) se ajustan de manera razonable al mecanismo de falla supuesto columna fuerte-viga débilcontraviento más débil. Es importante notar que las articulaciones plásticas presentes en la base de las columnas de planta baja se deben en gran parte a la condición de empotramiento perfecto supuesta en los análisis, que es difícil de lograr en una edificación real. Sin embargo, conforme los marcos incrementan su altura ( 20 y 24 niveles), se presentan algunas fluencias en los extremos de las columnas de los niveles inferiores (figuras 10d y 11d). Dichas rotaciones se desarrollan debido a la magnitud de la carga axial en las columnas exteriores, la cual es considerablemente mayor que aquélla presente en los modelos de menor altura. 
Se observa también que para los modelos de altura baja a mediana (cuatro a 16 niveles) el mayor trabajo inelástico se presenta en los entrepisos intermedios, en tanto que para los casos de los modelos de 20 y 24 niveles, este efecto se observa en el primer tercio de la altura de los marcos, coincidiendo con los entrepisos en que se presentan las mayores distorsiones (figuras 9, 10 y 11).

En los modelos de 20 y 24 niveles, conforme a los resultados expuestos, es necesario un ajuste en la metodología de diseño para prevenir la formación de articulaciones plásticas indeseables en las columnas de los niveles inferiores, o bien establecer un límite superior al aporte que a la resistencia cortante deben brindar las columnas del sistema para resistir las demandas sísmicas en función de la altura o la relación de esbeltez de la estructura $(H / L)$. Como lo han mostrado algunos autores (Bruneau 1998, Maheri y Akbari 2003, Tapia y Tena 2008), el comportamiento y modo de falla tanto de estructuras de acero como de concreto reforzado contraventeadas es dependiente de la altura.

Los resultados expuestos en esta sección, así como lo reportado en artículos previos (Godínez y Tena 2007 y 2009, Godínez y Tena 2008 y 2010), respaldan a la disposición general de las NTCS-04 de limitar la participación de los contravientos para aportar hasta un 50\% de la resistencia a cortante en marcos dúctiles, que en vista de los resultados obtenidos, parece adecuada. Sin embargo, los resultados son aplicables únicamente para modelos de baja y mediana altura (cuatro a 16 niveles), pues para los modelos de mayor altura (20 a 24 niveles), probablemente sea conveniente que el balance estipulado actualmente en las NTCS-04 variara conforme aumenta la altura de la estructura (o número de niveles), pero de una manera más general, en función del aumento de la relación de esbeltez $(H / L)$, o bien en función del periodo estructural, con lo cual se podrían considerar las diferencias entre las propiedades dinámicas de estructuras de diferentes alturas.

\section{Capacidades de deformación globales $\left(\mu_{\text {global }}\right)$}

A partir de las curvas cortante-distorsión globales se calcularon las capacidades de deformación global $\left(\mu_{\text {global }}\right.$ ). En la figura 12 se muestra la comparación de las capacidades de deformación global de todos los modelos considerados en el estudio, respecto al factor de comportamiento sísmico considerado en el diseño $(Q=4)$. Se observa que en varios casos la capacidad de deformación global es mayor que el factor de comportamiento sísmico de diseño $\left(\mu_{\text {global }}>Q\right)$, lo anterior principalmente en los modelos de cuatro y 12 niveles. En general, para los modelos de 16 a 24 niveles $\mu_{\text {global }} \leq Q$, independientemente del balance de resistencia considerado (figura 12).

De la figura 12 se observa que la capacidad de deformación inelástica del sistema dual decrece conforme se incrementa el porcentaje de fuerza cortante resistida por las diagonales de contraventeo, lo cual nuevamente sustenta la recomendación de las NTCS-04 referente a limitar a un valor máximo del $50 \%$ el aporte del sistema de contraventeo al cortante resistente para el diseño de marcos dúctiles.

\section{PARÁMETROS DE DISEÑO PROPUESTOS}

Como se comentó, en algunos casos las capacidades de deformación global $\left(\mu_{\text {global }}\right)$ resultaron mayores que el factor de comportamiento sísmico para el cual fueron diseñados $\left(\mu_{\text {global }}>Q\right.$, figura 12). Con la finalidad de obtener algunos parámetros útiles desde el punto de vista de diseño, es conveniente realizar estimaciones de algunos parámetros para una capacidad de deformación fija, en este caso la máxima permisible para el diseño de marcos dúctiles de concreto contraventeados $Q=4$. Por lo anterior, en los casos en que la capacidad de deformación global excedió la capacidad de deformación máxima 
considerada para diseño $(Q=4)$, los parámetros considerados de importancia fueron recalculados considerando una capacidad de deformación global máxima igual al factor de comportamiento sísmico considerado en el diseño.

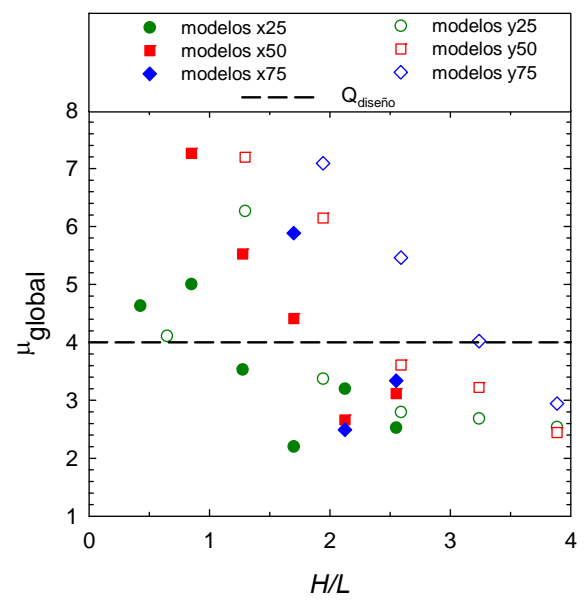

Figura 12. Relaciones entre la ductilidad global y la relación de esbeltez $(H / L)$

Con base en el ajuste realizado en las capacidades de deformación global de algunos de los modelos de cuatro a 16 niveles (los modelos de 20 y 24 niveles no sufrieron ajustes), se realizó el cálculo de algunos parámetros de interés, dentro de los que se encuentran: (1) factores de reducción por sobrerresistencia $(R),(2)$ distorsiones correspondientes a la fluencia $\left(\Delta_{\mathrm{y}}\right),(3)$ distorsiones máximas $\left(\Delta_{\max }\right)$ $\mathrm{y}$, (4) distribuciones de ductilidades de entrepiso $(\mu)$. Asimismo, se presenta una propuesta referente al porcentaje de fuerza cortante mínimo que las columnas de un entrepiso deben resistir en función de la relación de esbeltez de la estructura $(H / L)$, y otra en que se proponen dos expresiones para la estimación del periodo fundamental de vibración como función de la altura o el número de niveles.

Es importante destacar que los parámetros de diseño propuestos se estimaron con base únicamente en los resultados de los modelos en que las columnas de los marcos aportan como mínimo el 50\% de la resistencia a fuerza cortante (modelos con comportamiento dúctil), pues como se comentó, del estudio detallado de las curvas cortante-distorsión y de los mapeos de rotaciones plásticas acumuladas, se observó que el comportamiento de los modelos en que las columnas aportan un porcentaje menor al $50 \%$ de la resistencia a fuerza cortante (modelos $m N d 25$ ) no es satisfactorio para el diseño de sistemas dúctiles.

\section{Factor de reducción por sobrerresistencia $(R)$}

A partir de los resultados de las curvas cortante-distorsión ajustadas, se realizó el cálculo de los factores de reducción por sobrerresistencia ( $R=V_{u} V_{\text {dis }}$, figura 7) para el caso en que se consideran fuentes adicionales de sobrerresistencia (no existe variación importante respecto a los valores no ajustados). Con base en dichos resultados, se propone una expresión para la determinación de los factores de reducción por sobrerresistencia (ec. 2) para sistemas con base en marcos de concreto con contraventeo metálico tipo chevrón. La ecuación propuesta tiene la forma general con la cual se determinan los factores de reducción por sobrerresistencia en la nueva propuesta del Manual de Obras Civiles de la Comisión Federal de Electricidad (MOC-08 2009 y Tena et al. 2009), la cual pudiera ser adoptada en futuras versiones del Reglamento de Construcciones del Distrito Federal. Siguiendo dicho enfoque, en este caso se tendría un valor de $R_{0}=1.7$ y un valor $R_{1}=2.3$. 


$$
\begin{aligned}
& R=\left\{\begin{array}{lr}
1.7+2.3\left(1-\sqrt{T_{e} / T_{a}}\right) & \text { si } T_{e} \leq T_{a} \\
1.7 ; & \text { si } T_{e}>T_{a}
\end{array}\right. \\
& R=\left\{\begin{array}{lrl}
\frac{2.4}{\sqrt{H / L}} & \text { si } & 0.4 \leq H / L \leq 2.0 \\
1.7 ; & \text { si } H / L>2.0
\end{array}\right.
\end{aligned}
$$

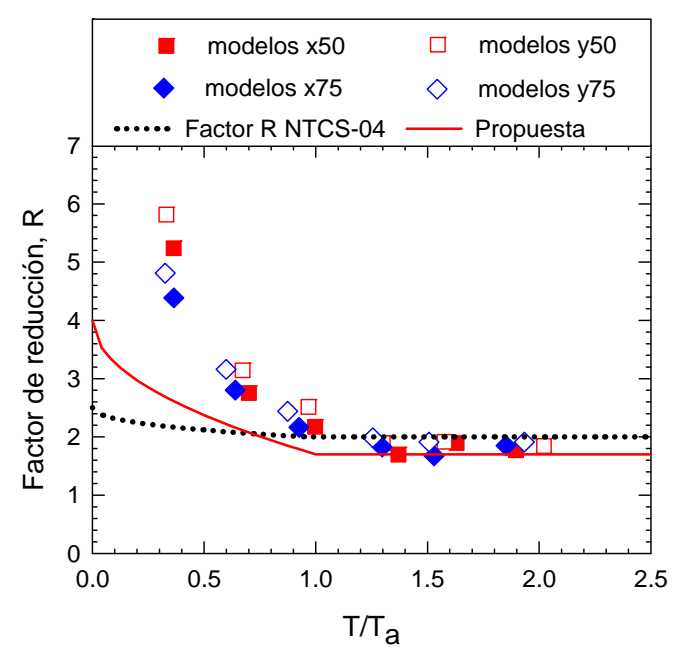

Figura 13. Propuesta par la determinación de factores de reducción por sobrerresistencia

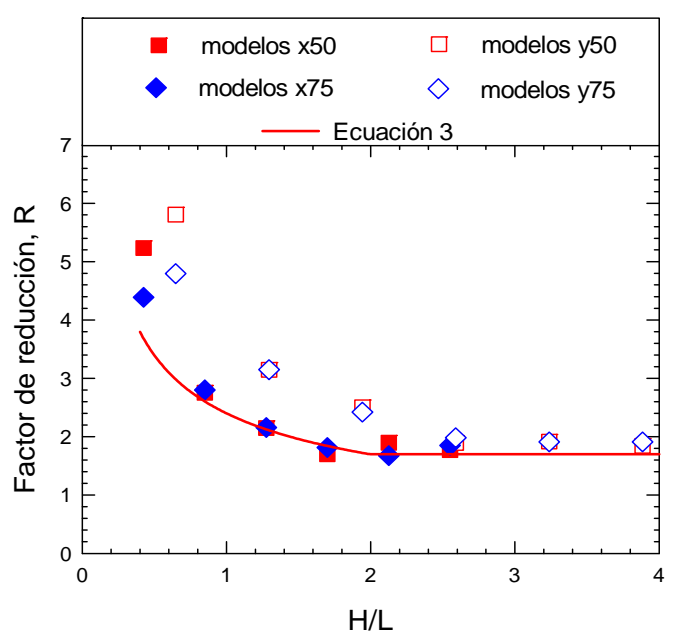

Figura 14. Relación entre los factores $\mathrm{R}$ y la relación de esbeltez $(\mathrm{H} / \mathrm{L})$

En la figura 13 se muestran los valores con base en los cuales se derivó la ecuación 2, así como las curvas descrita por dicha ecuación y la propuesta actual del Apéndice A (AA) de las NTCS-04. Se observa que la nueva propuesta es conservadora, pues en la mayoría de los casos, dicha curva se encuentra por debajo de los valores teóricos. Al comparar la curva propuesta con la correspondiente de las NTCS-04, se observa que la curva propuesta presenta valores superiores a los especificados en el AA para la zona de periodos cortos, en tanto que para la zona de periodos largos, se proponen valores menores a los actualmente considerados en las NTCS-04, obteniendo con esto valores más cercanos a los obtenidos teóricamente. La expresión propuesta está sustentada en evidencia analítica desarrollada específicamente para el sistema estructural considerado (Godínez 2010), a diferencia de la propuesta actual de las NTCS04, la cual fue propuesta considerando los valores obtenidos en unos cuantos modelos de marcos momento-resistentes de concreto reforzado.

Asimismo, en la figura 14 se presenta la relación entre los factores de reducción por sobrerresistencia $(R)$ ajustados y la relación de esbeltez $(H / L)$; así como una ecuación (ec. 3) que puede ser útil para realizar una estimación rápida de los factores $R$ esperados en función de la relación de esbeltez de la estructura. Es evidente que los factores de reducción por sobrerresistencia decrecen de manera significativa conforme se incrementa la relación de esbeltez y el periodo de la estructura. Se observa también, que para las estructuras más rígidas, conforme se incrementa el porcentaje de fuerza cortante que resisten las columnas, decrecen los valores de $R$. 


\section{Distorsión asociada al estado límite de servicio $\left(\Delta_{y}\right)$}

En las figuras $15 \mathrm{a}$ y $15 \mathrm{~b}$ se presentan las envolventes de distorsiones asociadas a la fluencia de cada entrepiso (para ambas direcciones de análisis), las cuales se estimaron con base en una curva bilineal idealizada de la curva cortante-distorsión real (figura 7). Como se comenta en Tena et al. (2008), la importancia de dichas envolventes radica en que en algunos códigos de diseño sísmico se emplea esta simple estrategia para la definición de parámetros de diseño. Es importante notar que en algunos casos ciertos entrepisos permanecen elásticos $(\mu=1)$, especialmente los entrepisos superiores.
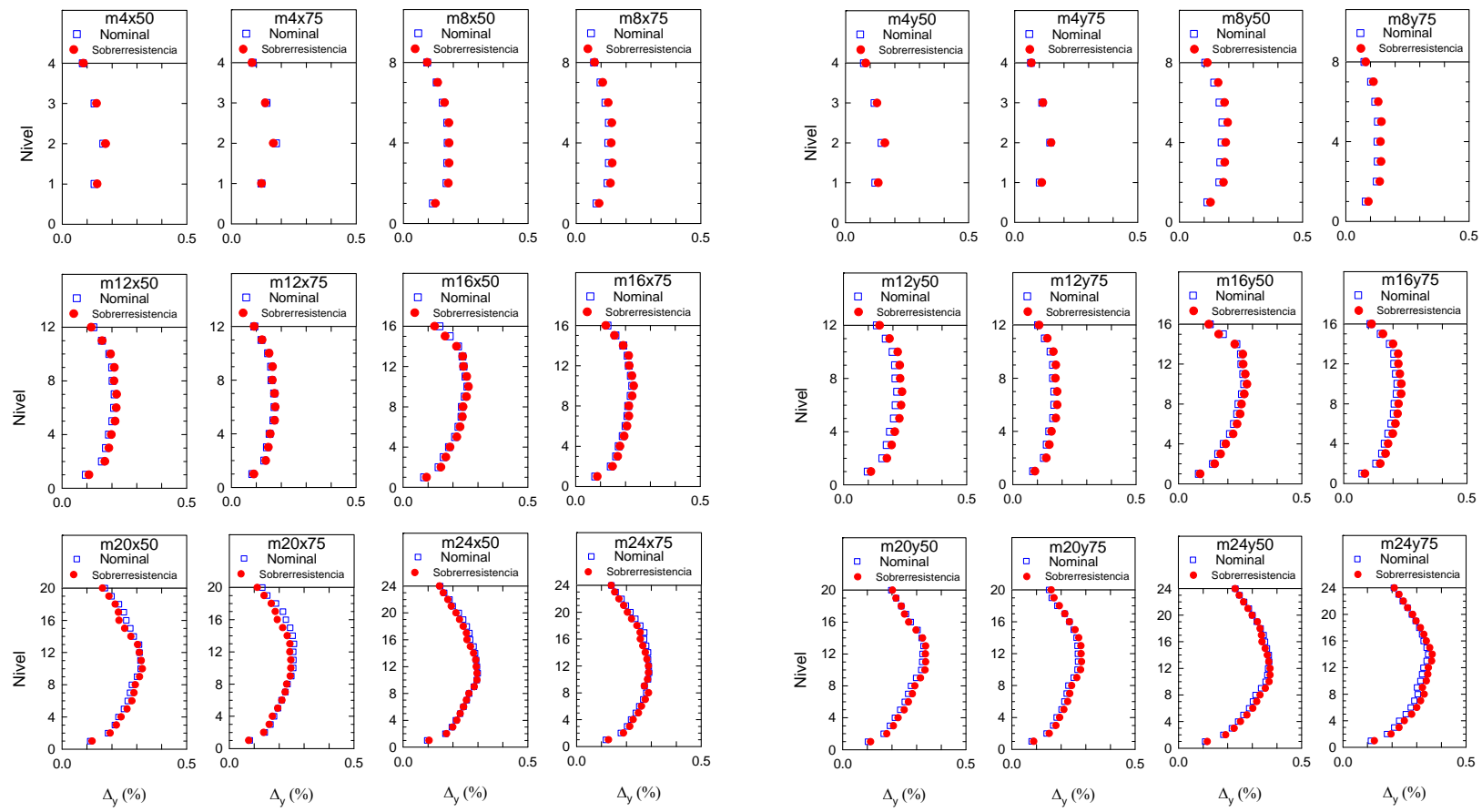

a) Modelos en dirección $X$

b) Modelos en dirección $Y$

Figura 15. Envolventes de distorsiones asociadas a la fluencia

De los resultados expuestos en la figura 15 se observa que, en general, las máximas distorsiones de fluencia $\left(\Delta_{y}\right)$ se presentan en la altura media de los marcos y estas tienden a incrementarse conforme la altura de los marcos crece. No se aprecia un efecto considerable de la sobrerresistencia en los valores calculados.

En todos los casos las distorsiones de fluencia son menores a la estipulada como distorsión límite de servicio en el Apéndice A de las NTCS-04 $\left(\Delta_{s e r}=0.004\right)$. Es importante mencionar que dicho límite se basa en estudios de marcos momento-resistentes, por lo que no es necesariamente comparable con los valores aquí presentados para marcos con contravientos de acero chevrón. Lo anterior muestra nuevamente la necesidad de definir parámetros de diseño específicos al sistema estructural en estudio.

Con el objeto de proponer una distorsión de fluencia límite para marcos de concreto reforzado con contraventeo concéntrico (chevrón), se calculó el promedio de las distorsiones de fluencia de cada uno de los entrepisos que presentaron comportamiento inelástico (no se incluyen los entrepisos que permanecen elásticos). Los resultados se presentan contra el periodo natural $(T)$ normalizado respecto al número de 
niveles de cada modelo en consideración $(N)$, el cual representa un parámetro simple de la rigidez (figura 16).

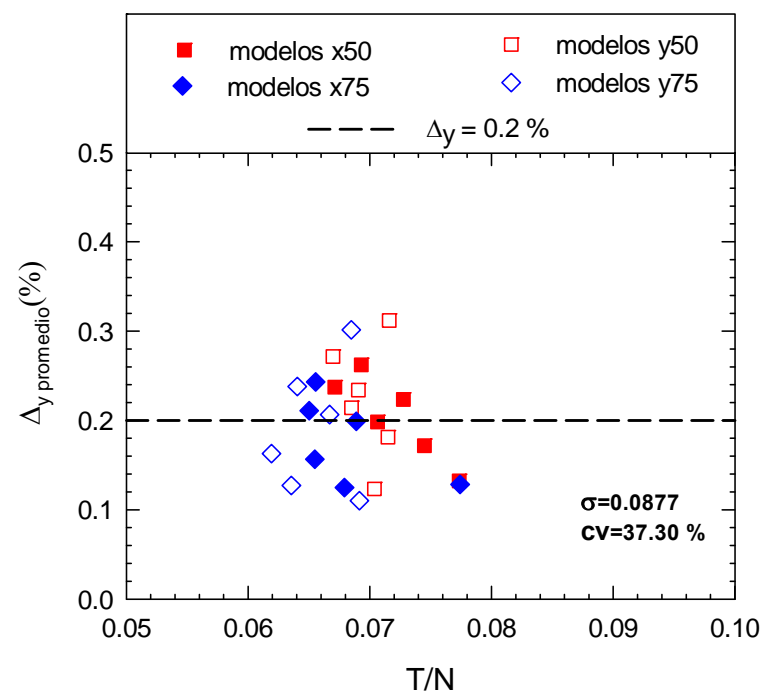

Figura 16. Propuesta para la distorsión de fluencia $\left(\Delta_{y}=0.002\right)$ asociada al estado límite de servicio

Debe notarse que para el cálculo de la distorsión promedio tampoco se incluyeron las distorsiones de entrepiso calculadas en el primer nivel, debido a la condición de frontera considerada (empotramiento en la base de las columnas). Con base en los cálculos realizados, se propone una distorsión de fluencia promedio $\Delta_{y}=0.002$, la cual representa el promedio de todas las distorsiones calculadas y se expresa mediante una línea recta horizontal en la figura 16. De la figura 15 se observa también que conforme se incrementa la altura de los modelos, la distorsión promedio crece. La distorsión media de fluencia propuesta ( $\Delta_{y}=0.002$ ) puede tomarse en cuenta para el diseño de sistemas duales con base en marcos de concreto reforzado y contraventeo metálico al realizar la revisión asociada al estado límite de servicio, ya que el límite propuesto toma en cuenta la rigidez específica (masa y/o periodo) del sistema estudiado, aspecto que no se toma en cuenta en la propuesta actual del AA de las NTCS-04.

\section{Distorsión asociada al estado límite de prevención de colapso $\left(\Delta_{\max }\right)$}

En la figura 17 se muestran las envolventes de distorsiones máximas de cada modelo, tanto al considerar resistencias nominales (N) como efectos de sobrerresistencia (S). Asimismo, se muestran las distorsiones de diseño (D). Las distorsiones máximas son las asociadas al criterio comentado previamente, en que se considera como capacidad de deformación máxima global la estipulada para diseño $(Q=4)$. Estas curvas brindan una idea razonable de la distorsión máxima que estos sistemas pueden desarrollar con fines de diseño.

Con base en las envolventes mostradas en la figura $17 \mathrm{y}$, con la finalidad de proponer una distorsión máxima de diseño para el sistema estructural en estudio, en la figura 18 se muestra el promedio de las distorsiones máximas de los entrepisos de los marcos en que se presentan los desplazamientos máximos respecto a la relación de esbeltez $(\mathrm{H} / \mathrm{L})$. Se observa que conforme se incrementa la relación de esbeltez y el periodo de los modelos, la distorsión máxima promedio crece. 

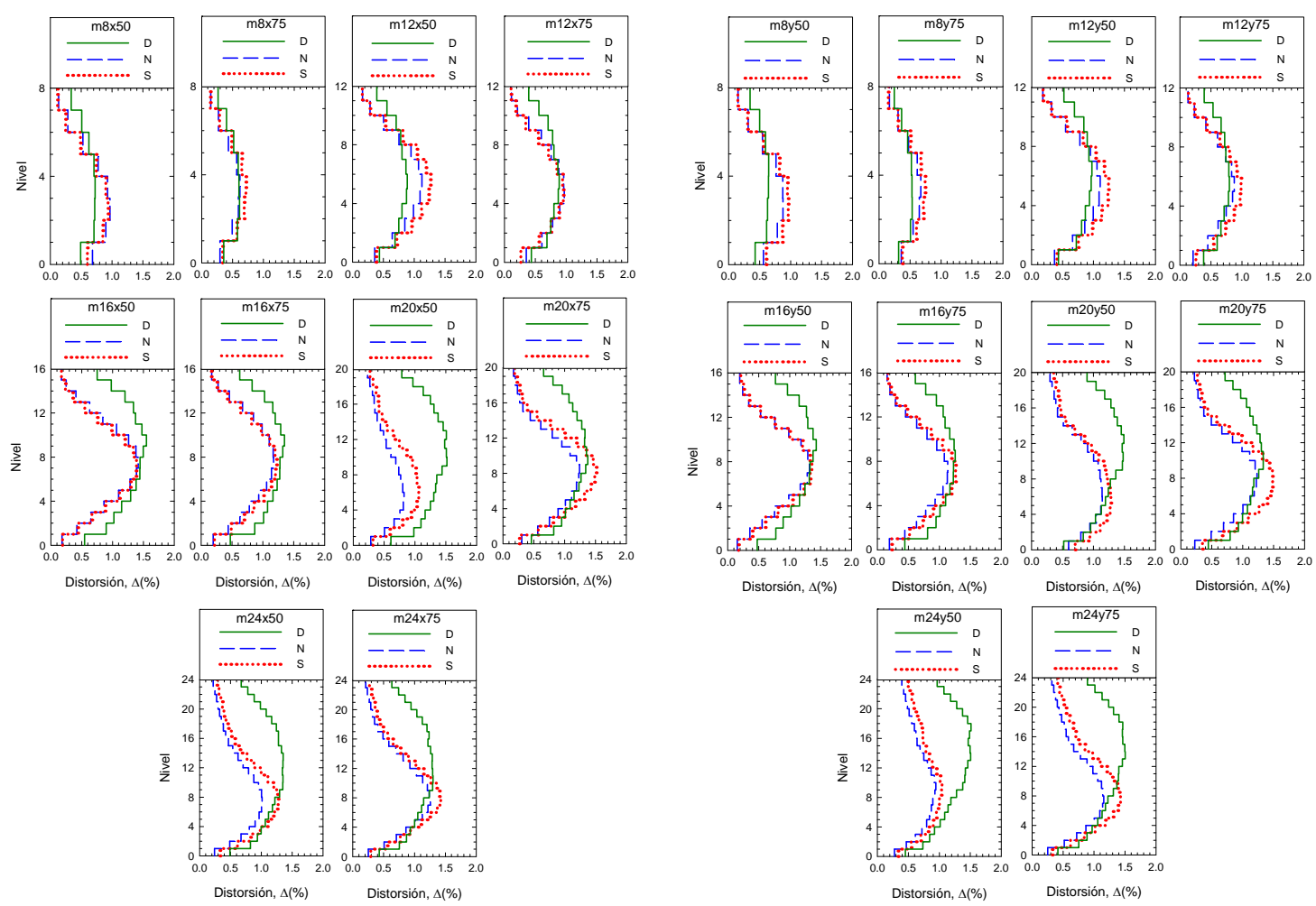

a) Modelos en dirección $X$

b) Modelos en dirección $Y$

Figura 17. Envolventes de distorsiones de diseño (D), nominales (N) y con sobrerresistencia (S)

Con base en los resultados expuestos (figuras 17 y 18), se propone una distorsión máxima de diseño (asociada al estado límite de colapso) igual a $\Delta_{\max }=0.013$, la cual representa el promedio de las distorsiones consideradas y se expresa mediante una línea recta horizontal en la figura 18. El promedio calculado considera los modelos cuyo comportamiento está regido principalmente por el efecto de carga lateral.

Es importante hacer notar que el valor propuesto para la revisión del estado límite de colapso es inferior al valor $\Delta_{\max }=0.015$ actualmente establecido en algunos códigos internacionales (por ejemplo ASCE 7-05, 2005) y en el Apéndice A de las NTCS-04, por lo que en la siguiente etapa de este estudio, en que se realizarán análisis dinámicos no lineales, se valorará cual de los dos límites resulta más adecuado para el diseño de estos sistemas estructurales.

\section{Capacidad de deformación inelástica (ductilidades de entrepiso, $\mu$ )}

De forma complementaria a las dos secciones precedentes, en la figura 19 se muestran las ductilidades de entrepiso para ambas direcciones de análisis. Por simplicidad, aquellos entrepisos donde la respuesta es elástica se identifican mediante $\mu=1$. 


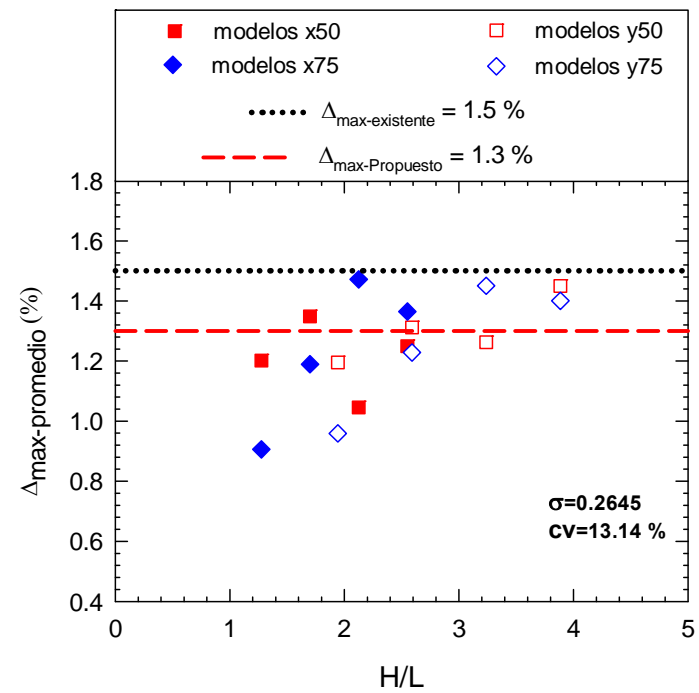

Figura 18. Propuesta para la distorsión máxima de diseño $\left(\Delta_{\max }=0.013\right)$ asociada al estado límite de seguridad contra colapso

De los resultados expuestos se hacen las siguientes observaciones:

(1) Para la mayoría de los modelos las ductilidades disponibles no son uniformes. Para los modelos de cuatro a 16 niveles, las mayores capacidades de deformación se localizan en los entrepisos intermedios (entrepisos 2 a 4 en los modelos de ocho niveles y entrepisos 3 a 5 en los modelos de 12 niveles). Sin embargo, para los modelos de 20 a 24 niveles, las mayores capacidades de deformación se localizan en los entrepisos ubicados en el primer tercio de la altura (entrepisos 6 a 8). Como se ha observado también en otros sistemas estructurales (por ejemplo, marcos momentoresistentes), la capacidad de deformación decrece en los entrepisos superiores, encontrando en varios casos comportamiento muy cercano al elástico.

(2) En los modelos en que las columnas resisten aproximadamente el $50 \%$ de la fuerza cortante total, la capacidad de deformación inelástica es menor a la obtenida para los casos en que las columnas resisten aproximadamente el $75 \%$ de la fuerza cortante total. Es decir, la capacidad de deformación inelástica decrece conforme se incrementa el aporte del sistema de contraventeo para resistir las fuerzas laterales.

(3) En general, las capacidades de deformación inelásticas (ductilidades) calculadas considerando fuentes adicionales de sobrerresistencia son mayores respecto a las calculadas al considerar resistencias nominales. Los resultados para ambas direcciones de análisis son similares.

\section{Aporte mínimo de las columnas al cortante resistente del sistema ante carga lateral}

Como se ha comentado, de acuerdo a lo actualmente estipulado en las NTCS-04 para el diseño estructuras dúctiles en que la resistencia en todos los entrepisos es suministrada por marcos contraventeados, se requiere que en cada entrepiso los marcos sean capaces de resistir, sin contar con contravientos, cuando menos 50 por ciento de la fuerza sísmica actuante, independientemente de la relación de esbeltez de la estructura considerada. De los resultados obtenidos, dicha disposición parece razonable para estructuras de baja y mediana altura (cuatro a 16 niveles) diseñadas con base en criterios de diseño por capacidad. 

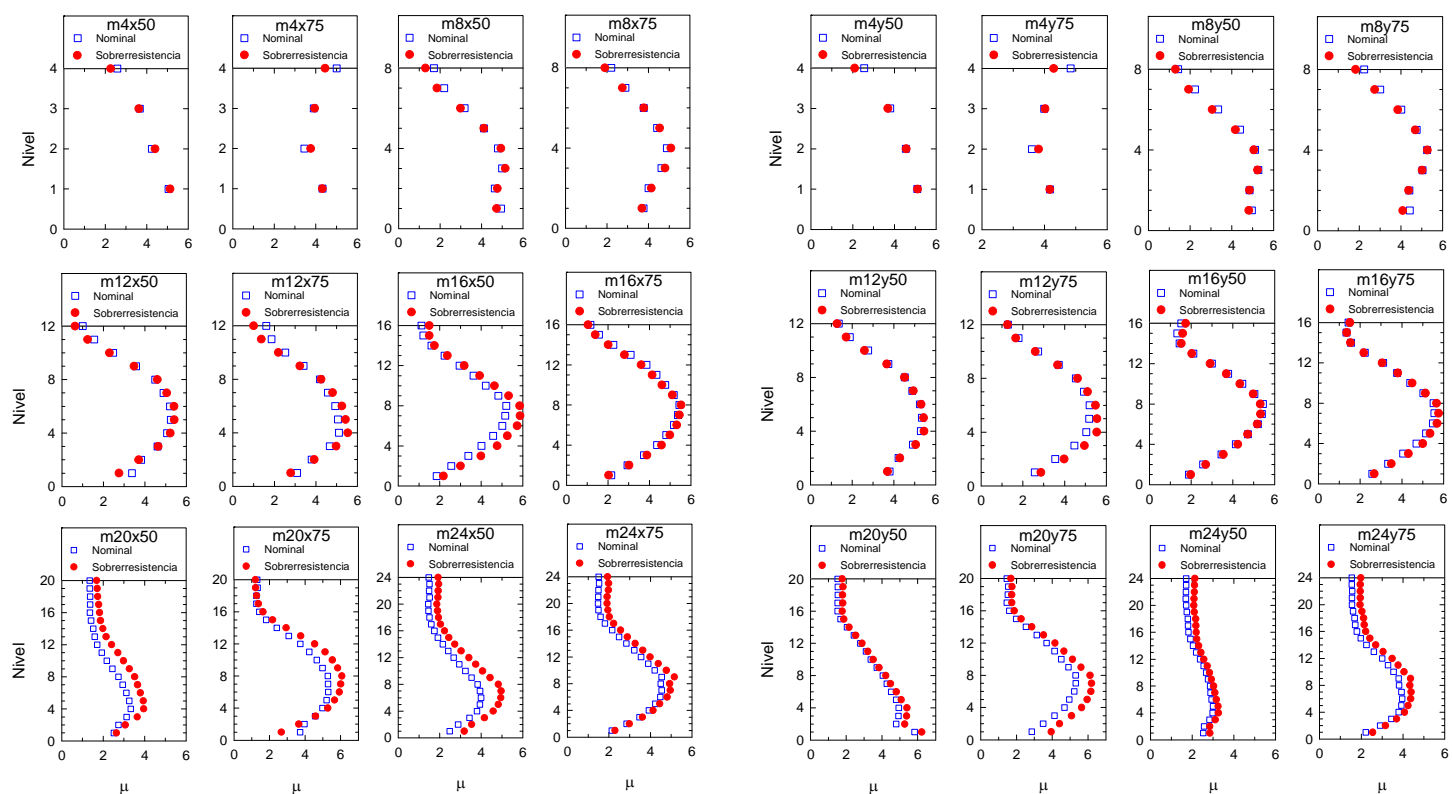

a) Modelos en dirección $X$

b) Modelos en dirección $Y$

Figura 19. Envolventes de capacidades de deformación inelástica $(\mu)$

Sin embargo, dicha disposición no resulta completamente adecuada para que estructuras de mayor altura (20 niveles o mayores) garanticen un comportamiento dúctil con contravientos convencionales que experimentan pandeo, por lo cual este rubro podría ajustarse con la finalidad de prevenir la formación de articulaciones plásticas en las columnas de entrepisos inferiores. Varios investigadores han evaluado el efecto que la altura tiene en el comportamiento estructural, principalmente para el caso de estructuras metálicas (por ejemplo, Khatib et al. 1988, Bruneau et al. 1998, Elghazouli 2003, Tapia y Tena 2008) y en menor medida para estructuras de concreto reforzado contraventeadas (Maheri y Akbari 2003). En los estudios citados se muestra una dependencia de la altura en los mecanismos de colapso observados. De los resultados expuestos en este estudio, se observa también una dependencia del comportamiento estructural conforme se incrementa la relación de esbeltez y el periodo de los marcos considerados.

Por lo anterior, con base en el estudio de los mecanismos de colapso, de los balances de resistencia para los que fueron diseñados cada uno de los modelos en estudio, así como de la información complementaria disponible y procesada, se propone una ecuación simple en función de la relación de esbeltez de la estructura $(H / L)$, para la estimación del porcentaje mínimo de resistencia a fuerza cortante que las columnas de un entrepiso deben ser capaces de aportar en el sistema dual (ecuación 4). Con lo anterior se busca que los mecanismos de colapso obtenidos sean congruentes con la filosofía de diseño, es decir, columnas fuerte-viga débil-contraviento más débil. La ecuación 4 es válida para relaciones de esbeltez $0.4 \leq \mathrm{H} / \mathrm{L} \leq 4 \quad(0.203 \leq \mathrm{T} \leq 1.774)$, intervalo en que se encuentran los marcos estudiados y para los cortantes basales de diseño de la zona III-b considerando un factor de comportamiento sísmico $Q=4$.

$V_{R C o l} \geq 50+1.2\left(\frac{H}{L}\right)^{2}$

donde: 
$V_{R C o l}=$ Aportación mínima de las columnas de un entrepiso al cortante resistente, en porcentaje.

$H=$ Altura total del edificio.

$L=$ Longitud de la base de la estructura en el sentido de análisis.

Como se comentó, la propuesta intenta fomentar un comportamiento dúctil evitando en lo posible el daño en columnas, concentrando la disipación de energía en los contravientos y vigas, que con base en el mecanismo de falla supuesto, corresponde al comportamiento estructural deseado.

En la figura 20 se presenta la curva descrita por la ecuación propuesta (ec. 4). Asimismo, se muestran los balances de resistencia para los cuales fueron diseñados la totalidad de los modelos en estudio, a partir de los cuales se derivó dicha ecuación. Debe notarse que en la regresión realizada únicamente se consideraron los resultados de los modelos en que las columnas aportan como mínimo el $50 \%$ de la resistencia a cortante de entrepiso.

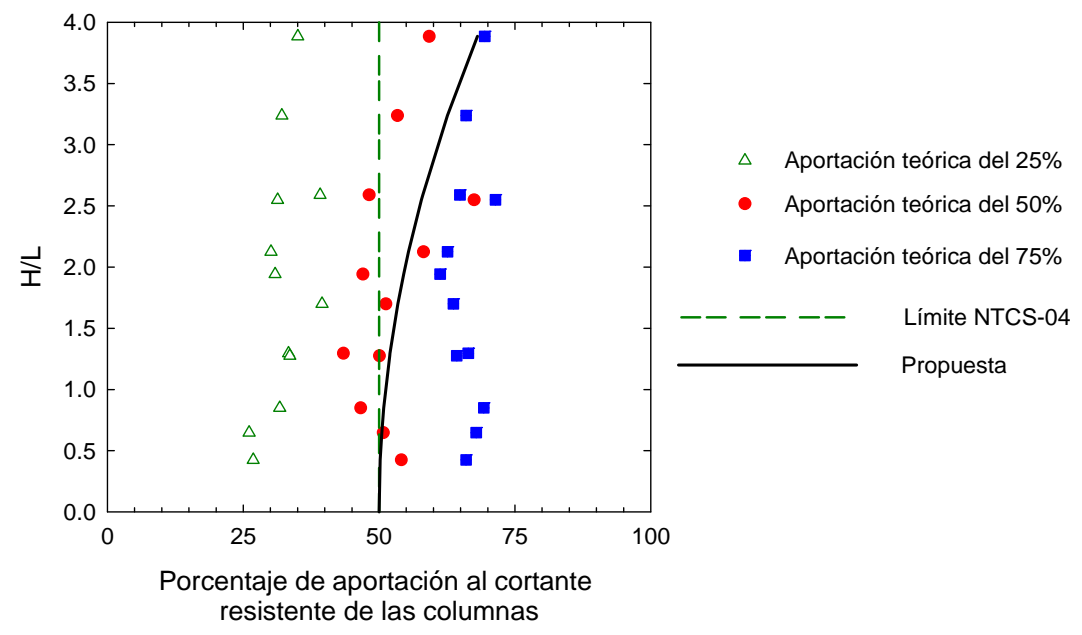

Figura 20. Propuesta del aporte mínimo de las columnas de un entrepiso al cortante resistente

Sin embargo, debe considerarse que la propuesta anterior por sí misma no es suficiente para obtener mecanismos de colapso consistentes con los esperados, dado que el comportamiento inelástico del sistema estructural en estudio (como de cualquier otro) está influenciado por diferentes parámetros, como la capacidad de deformación de las vigas, la potencial axialización de las columnas (que limitan su capacidad de deformación), la relación de esbeltez empleada en las diagonales de contraventeo (que impactan su modo de falla en pandeo), las condiciones de compacidad y el grado del acero, así como la configuración seleccionada para realizar las conexiones. Sin embargo, éste puede considerarse como un buen punto de partida para ayudar en lo posible a la formación de mecanismos de colapso consistentes con los estipulados en las premisas de diseño para marcos de concreto reforzado contraventeados.

\section{Estimación del periodo fundamental}

En esta sección se proponen dos ecuaciones para la estimación del periodo fundamental en base rígida. Para la determinación de las ecuaciones propuestas se emplearon los periodos fundamentales de los marcos estudiados, los cuales están en el intervalo de los cuatro a 24 niveles, por lo que es en dicho intervalo en que la ecuación propuesta tiene mayor aplicación. 
En las figuras 21 a y $21 \mathrm{~b}$ se muestra la tendencia de los periodos de vibrar conforme se incrementa tanto el número de niveles, como la altura de los marcos. Como se observa, una relación lineal representa de manera razonable y simple el comportamiento observado en ambos casos. Con base en esto, se proponen dos expresiones simples (ecuaciones 5 y 6) para la estimación de los periodos de vibrar de sistemas duales con base en marcos de concreto reforzado con contraventeo metálico tipo chevrón en función del número de niveles $(N)$ y la altura $(H)$, respectivamente. Las ecuaciones propuestas se representan en las figuras $21 \mathrm{a}$ y $21 \mathrm{~b}$ mediante una línea recta. Como era de esperarse, debido a la rigidez de este tipo de estructuras, los periodos calculados con base en la ecuación propuesta son menores que los calculados con base en expresiones similares (Murià y González, 1995) para el caso de estructuras con base en marcos momento-resistentes.

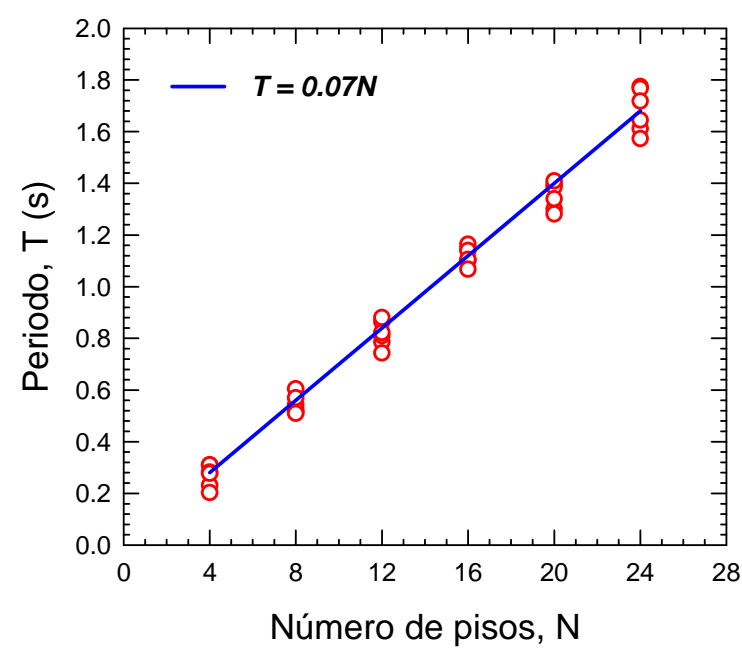

a)

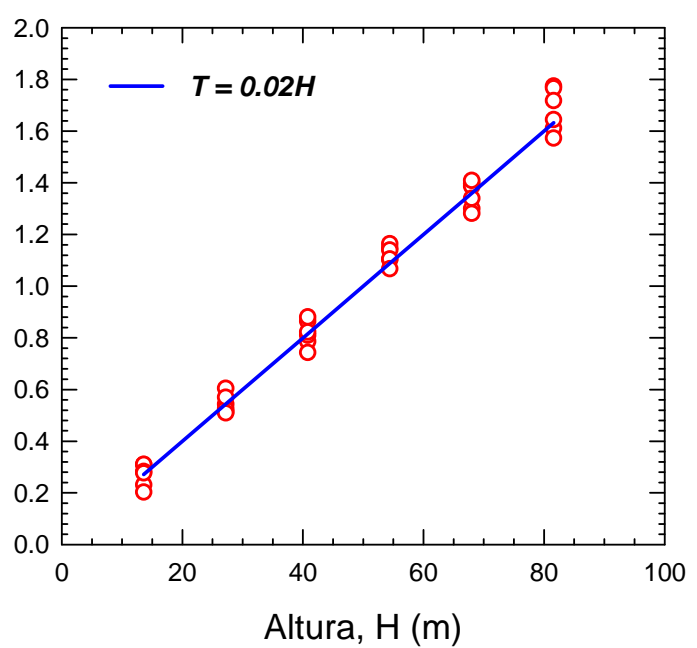

b)

Figura 21. Relación entre periodos fundamentales de vibrar y a) el número de niveles y, b) la altura en base rígida

$T=0.07 N$

$T=0.02 H$

donde:

$T=$ Periodo fundamental de vibración en base rígida

$N=$ Número de pisos del edificio

$H=$ Altura total del edificio (en metros)

\section{REVISIÓN DE LA METODOLOGÍA A NIVEL ELEMENTO. COMENTARIOS Y AJUSTES PROPUESTOS}

Por cuestiones de espacio, en esta sección se presentan únicamente algunos de los resultados más relevantes de la evaluación de la metodología de diseño a nivel elemento, la cual se realizó también con base en los resultados de análisis no lineales ante carga monótona creciente. Con base en los resultados obtenidos, es posible determinar si algunas de las premisas de diseño son adecuadas o requieren adaptaciones, las cuales lleven a un diseño más eficiente. Los resultados de esta parte del estudio se reportan con detalle en Godínez (2010). 


\section{Diseño por flexocompresión en columnas}

Como se ilustra en el croquis de la figura 22, en cada gráfica expuesta en esta sección se presentan las relaciones carga axial - momento flexionante registradas durante el análisis estático no lineal de las columnas de planta baja. Asimismo, se muestran los diagramas de interacción de diseño y los obtenidos al considerar fuentes de sobrerresistencia. Se indican también, mediante líneas rectas horizontales, tanto el límite asociado a la carga axial máxima de diseño considerada ( $P_{\max }=0.5 A_{g} f_{c}^{\prime} / 10$ ), como el límite de carga axial a partir del cual, conforme a las NTCC-04, un elemento debe diseñarse como un miembro en flexocompresión ( $P=A_{g} f_{c}^{\prime} / 10$ ). Estos dos últimos límites se emplearon para valorar si, en efecto, los elementos estudiados se comportan tal y como se predijo en las premisas de diseño, pues por ejemplo, en el caso que las columnas estudiadas excedieran significativamente el límite de carga axial máximo especificado, indicaría que su comportamiento no es del todo satisfactorio, pues su modo de falla sería poco deseable de acuerdo con los objetivos de diseño planteados inicialmente, en los cuales se busca un comportamiento dúctil.

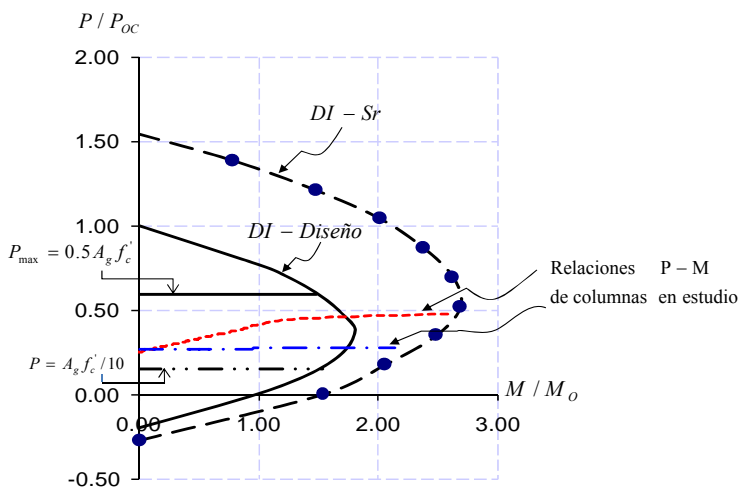

Figura 22. Croquis descriptivo para identificación de curvas

En la figura 23 se presentan las relaciones carga axial - momento flexionante normalizadas ( $P / P_{O C}$ vs $M / M_{O}$ ) obtenidas en las columnas de borde de planta baja de los modelos de cuatro a 24 niveles en dirección $X . P_{o c}$ y $M_{o}$ son respectivamente la carga axial máxima de compresión y el momento de flexión pura. Los resultados corresponden a los modelos en que las columnas aportan aproximadamente el $50 \%$ de la resistencia a cortante de entrepiso.

Para los modelos comprendidos entre los cuatro y 16 niveles (figura 23), en la mayoría de los casos, el comportamiento de las columnas se considera adecuado, pues las historias de carga axial-momento flexionante se encuentran dentro límites aceptables tanto de carga axial como de flexión, pues en ningún caso se excede la carga máxima permisible $\left(P_{\max }=0.5 A_{g} f_{c}^{\prime}\right)$ ni la capacidad a flexión definida por los diagramas de interacción que consideran efectos de sobrerresistencia.

Conforme a los resultados obtenidos (figura 23), para los marcos de entre cuatro y 16 niveles, el diseño por flexocompresión resultó adecuado, lo que indica que la metodología propuesta para estimar las cargas axiales (en la cual se considera la carga axial transmitida del sistema de contraventeo a las columnas) y los momentos flexionantes de diseño es adecuada. 


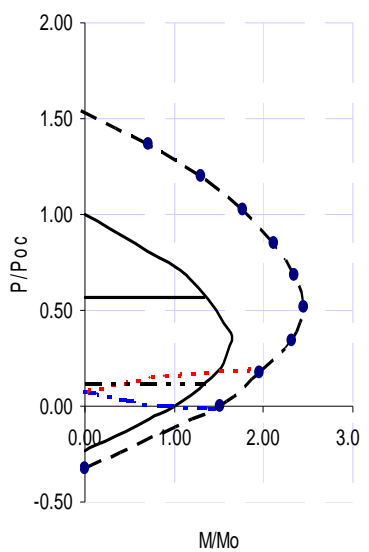

a) $\mathrm{m} 4 \times 50 \mathrm{sr}$

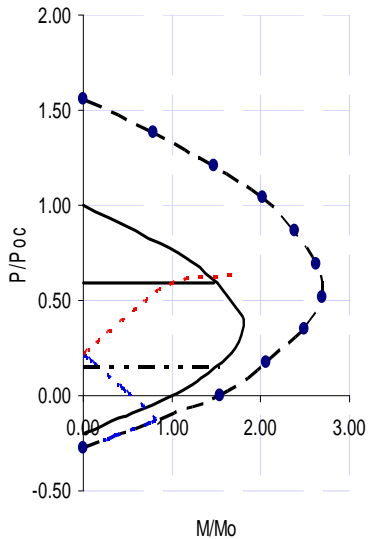

d) $\mathrm{m} 16 \mathrm{x} 50 \mathrm{sr}$

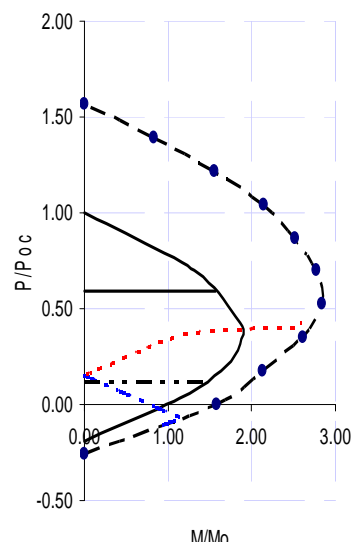

b) $\mathrm{m} 8 \times 50 \mathrm{sr}$

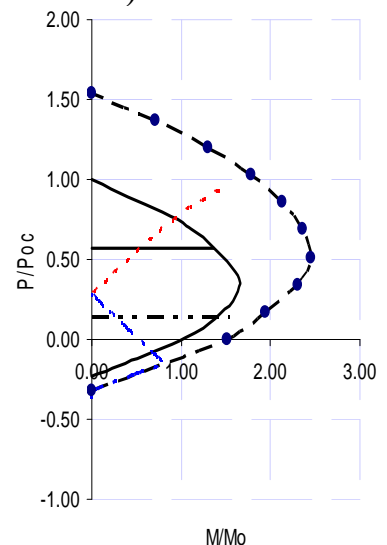

e) $\mathrm{m} 20 \mathrm{x} 50 \mathrm{sr}$

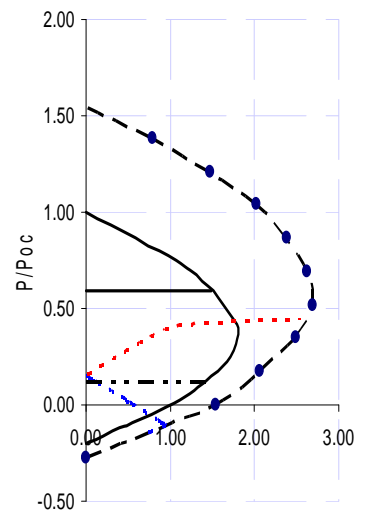

c) $\mathrm{m} 12 \times 50 \mathrm{sr}$

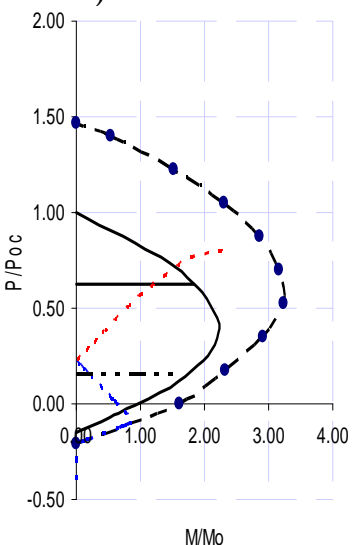

f) $\mathrm{m} 24 \times 50 \mathrm{sr}$

Figura 23. Relaciones $P / P_{O C}$ vs $M / M_{O}$ en columnas de los modelos de ocho niveles

Respecto a los modelos de mayor altura (20 y 24 niveles), los niveles de carga axial observados en las columnas de borde se incrementan de manera importante respecto a los modelos de menor altura, en especial en los modelos en que las columnas resisten aproximadamente el $50 \%$ de la carga lateral (figuras 23 e y 23f). Esto, como se mencionó, se debe a que para este balance de resistencia se consideran contravientos más robustos que para el caso en que las columnas aportan aproximadamente el $75 \%$ de la resistencia a fuerza cortante de entrepiso.

De las figuras $23 \mathrm{e}$ y $23 \mathrm{f}$ se observa que en algunas de las columnas de los marcos de 20 y 24 niveles se excede la carga máxima permisible (en algunos casos muy ligeramente). Lo anterior pudiese indicar que para los modelos de mayor altura, o visto de otra manera, en los modelos con mayor relación de esbeltez $(H / L)$, podría reconsiderarse la forma en que se estima la carga axial de diseño, posiblemente incrementando dicha carga por efecto de esbeltez del marco, pues debe notarse que la relación de esbeltez $(H / L)$ de los algunos de los modelos de 20 y 24 niveles no cumplen con el inciso $b$ del apartado 6 de las NTCS-04 referente a las condiciones de regularidad, donde se especifica que la relación altura a base menor no debe exceder de $2.5(H / L \leq 2.5)$ para que una estructura sea considerada como regular.

Con fines de valorar los niveles en que debería incrementarse la carga axial de diseño por efecto de esbeltez, en la figura 24 se muestran, para las columnas de planta baja, los valores de carga axial última actuante normalizada respecto a la carga máxima permisible de diseño $\left(P_{u} / P_{\max }\right)$ contra la relación de 
esbeltez de los modelos $(H / L)$. Los valores mostrados corresponden únicamente a una de las columnas de esquina o borde de cada modelo, la cual representa la situación más desfavorable, es decir, aquélla donde se presentan los mayores valores del factor $P_{u} / P_{\max }$. Se indican con símbolos circulares vacíos aquellos valores inferiores a la unidad, es decir, aquellos valores en que la carga axial en las columnas es menor o igual a la carga máxima permisible de diseño. Asimismo, mediante cuadros llenos se indican los valores superiores a la unidad, donde la carga axial excede la carga axial máxima permisible de diseño. En general, estos casos corresponden a estructuras con una relación de esbeltez mayor a $2.5(H / L>2.5)$, por lo que acorde al apartado 6 de las NTCS-04, estas estructuras deben considerarse como irregulares. Para dichos valores se obtuvo el valor de la media, la cual se indica también en la figura 24 mediante una línea horizontal $(\bar{x}=1.3)$.

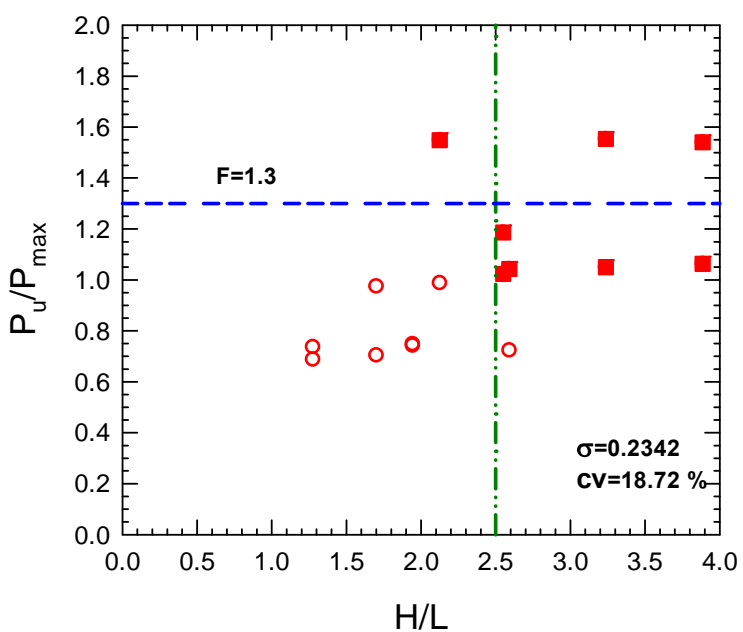

Figura 24. Propuesta para el incremento de la carga axial de diseño en columnas de esquina o borde de los primeros entrepisos en estructuras esbeltas $(H / L>2.5)$

Con base en lo expuesto y en el conjunto de resultados obtenidos (Godínez 2010), se propone que para estructuras que se consideran como irregulares en elevación $(H / L>2.5)$ la carga axial de diseño en columnas de borde o esquina de los primeros entrepisos se incremente en un 30\%, lo cual, en general, permitirá que las columnas no excedan un límite aceptable de carga axial (ec. 7).

$P_{\text {Diseño }}=\left\{\begin{array}{lll}P & \text { si } & H / L \leq 2.5 \\ 1.3 P & \text { si } & H / L>2.5\end{array}\right.$

\section{Diseño por cortante en columnas}

Respecto al diseño por fuera cortante, en la figura 25 se presentan los máximos valores de fuerza cortante observados en una de las columnas de planta baja estudiadas para cada uno de los modelos considerados (la más desfavorable). De los resultados expuestos en las figura 25 , se observa que en todos los modelos la demanda de fuerza cortante de cada uno de las columnas estudiadas no exceden el $50 \%$ de la fuerza cortante de diseño, es decir, en todos los casos los factores $V / V_{\text {dis }}$ son menores que 0.5 .

Se observa que el diseño por fuerza cortante realizado según lo estipulado en el apartado 7.3.5.1 de las NTCC-04 puede resultar en algunos casos muy conservador, pues la ocurrencia de una falla por fuerza cortante, en una columnas adecuadamente confinada, es poco probable conforme a lo observado (figura 
25). Probablemente el realizar el diseño por fuerza cortante considerando un factor de resistencia unitario y una sobrerresistencia del acero de refuerzo de $1.25 F_{y}$, únicamente conduce a diseños menos eficientes, pues como se muestra en esta sección, las demandas de fuerza cortante en las columnas son inferiores al $50 \%$ de la fuerza cortante de diseño. Lo anterior, indica que este rubro debe estudiarse con más detalle, tanto analítica como experimentalmente. De ser posible, es recomendable que en estudios posteriores se considere la interacción entre elementos mecánicos y no únicamente el estudio aislado de los mismos. Dichos estudios podrían brindar los elementos de juicio suficientes para definir si el diseño por fuerza cortante no lidera el diseño de este tipo de elementos, evitando con esto el sobrediseño por este concepto. Asimismo, el estudio del factor a empleado para definir la relación entre los momentos resistentes a flexión de columnas y vigas para garantizar un mecanismo de columna fuerte - viga débil, tendría impacto directo en el diseño por cortante, pues es obvio que cuando rige la recomendación reglamentaria que exige el sobrediseño de la capacidad a flexión de las columnas con respecto a las vigas (factor $\alpha=1.5$, ecuación 1), esto también conduce a que se sobrediseñen notablemente las columnas a cortante cuando éste se obtiene a partir del equilibrio de estos momentos amplificados de diseño. Por tanto, tal y como lo sugiere un estudio de carácter exploratorio (Castro et al. 2005), el factor $\alpha$ podría variarse con la altura y la esbeltez de la estructura.

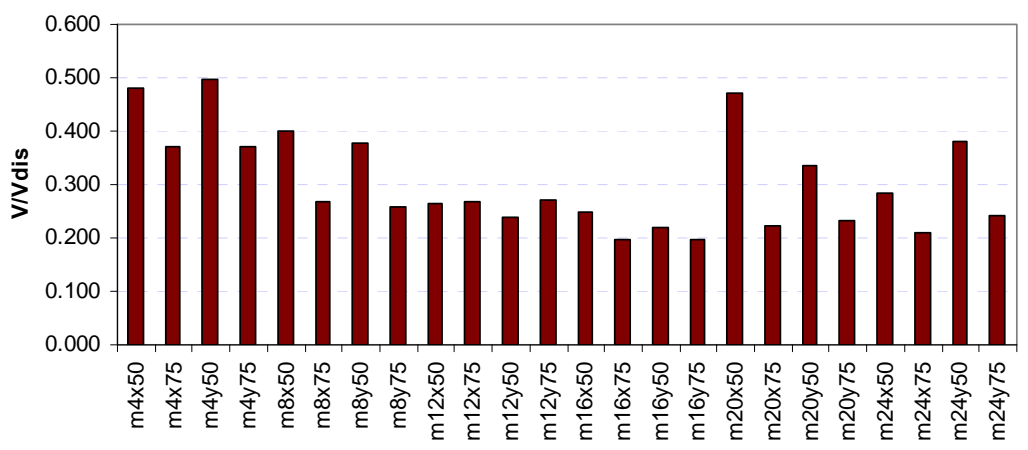

Figura 25. Máximos valores de $V / V_{\text {dis }}$ para cada uno de los modelos estudiados

\section{Diseño por flexión y cortante en vigas}

Respecto al diseño de las vigas, el segundo grupo de elementos a diseñar conforme al mecanismo de colapso esperado, con base en el conjunto de resultados obtenidos (Godínez 2010), se observó que la metodología de diseño por capacidad planteada inicialmente tanto para el diseño por flexión como para el diseño por fuerza cortante, es adecuada, por lo que no se requieren de ajustes en estos rubros.

\section{Diseño de los contravientos metálicos}

Como se indica en la literatura especializada (Black et al. 1980, Ikeda y Mahin 1984, Bruneau et al. 1998, etc.), parte importante del comportamiento inelástico de un marco contraventeado está definido por el comportamiento de los contravientos, cuyo comportamiento está influenciado, entre otros aspectos, por la forma de su sección transversal, su resistencia relativa a tensión y compresión y su relación de esbeltez $(k l / r)$.

En esta sección se presenta una recomendación de diseño enfocada en las relaciones de esbeltez de los elementos que conforman el sistema de contraventeo, que según los resultados obtenidos, son en su mayoría adecuadas para obtener un comportamiento estructural satisfactorio. La determinación de las capacidades a tensión y compresión de elementos sujetos a carga axial ha sido ampliamente estudiada y, 
las recomendaciones para realizar dichas estimaciones con fines de diseño se encuentran estipuladas en los códigos de diseño (por ejemplo, NTCEM-04 2004 y LRFD-01 2001).

Las secciones empleadas en los contravientos deben cumplir con los requisitos de sección compacta, pues deben evitarse fallas prematuras debidas a pandeo local. En la figura 26 se muestran las relaciones ancho grueso $(b / t)$ respecto a su relación de esbeltez. Como se comentó, en todos los casos se emplearon secciones cajón considerando acero tipo A-36. Es importante considerar que el empleo de aceros de alta resistencia no es recomendable en el diseño de contravientos, pues además de que los límites de compacidad se reducen, al incrementarse los esfuerzos de fluencia, el mecanismo de colapso puede modificarse, ya que estos elementos podrían no ser los primeros en fluir, lo cual no es deseable. Asimismo, la carga axial que los contravientos transmitirían a las columnas podría incrementarse, lo cual a su vez impactaría en el diseño de la cimentación. Como se observa, en todos los casos la sección es compacta y únicamente existen un modelo en que se exploró la posibilidad de tener relaciones de esbeltez ligeramente superiores a las máximas estipuladas en las NTCEM-04, pero aún comprendidas en el intervalo considerado por otro código internacional, como lo es el canadiense (CISC-08 2008).

Para obtener una idea del intervalo de relaciones de esbeltez recomendables para diseño, se realizó una regresión lineal de los datos empleados para el diseño de los marcos de cuatro a 24 niveles, en el que se emplearon generalmente relaciones de esbeltez que oscilan entre 50 y $150(50 \leq k l / r \leq 150)$. De los resultados obtenidos y expuestos en diversas secciones, se ha comentado que no es recomendable el empleo de secciones con relaciones de esbeltez muy bajas, debido a las grandes cargas axiales que pueden transmitirse del sistema de contraventeo a las columnas, lo cual reduce significativamente la capacidad de deformación del sistema. Por otra parte, tampoco es recomendable el empleo de secciones con relaciones de esbeltez muy altas, pues su comportamiento cíclico se vería seriamente afectado por el efecto del pandeo elástico (Black et al. 1980, Ikeda y Mahin 1984 y Bruneau et al. 1998). Además, el empleo de relaciones de esbeltez muy altas se ve reflejado en los niveles a que se alcanzan las distorsiones de fluencia (global y de entrepiso), pues ésta se reduce conforme la relación de esbeltez crece.

En la figura 27 se muestran la relación entre la fuerza de tensión $(T)$ normalizada respecto a la resistencia de compresión nominal (carga de pandeo, $R_{c}$ ) contra la relación de esbeltez en las diagonales de contraventeo $(\mathrm{kl} / \mathrm{r})$. Se presentan únicamente valores iguales o superiores a la unidad, es decir, valores en que la fuerza de tensión es igual o superior a la carga de pandeo.

Si se considera que la relación entre la fuerza de tensión y la carga de pandeo puede ser como máximo 1.5 veces, es decir, que la fuerza de tensión sea 50\% mayor que la carga de pandeo, de la figura 26 se obtienen relaciones de esbeltez recomendables para diseño entre 80 y 100, las cuales corresponden a los casos en que la fuerza de tensión es igual a la carga de pandeo y al caso en que la fuerza de tensión es $50 \%$ mayor que la carga de pandeo, respectivamente. Recordando que el coeficiente de columna $\left(C_{c}\right)$ define el punto teórico que separa al pandeo elástico $\left(k l / r>C_{c}\right)$ del inelástico $\left(k l / r<C_{c}\right)$, y que el pandeo elástico debe evitarse, la recomendación parece razonable, pues para el acero A-36, $C_{c}=126.1$. Badoux y Jirsa (1990), con base en estudios analíticos y experimentales, recomiendan limitar las relaciones de esbeltez $(\mathrm{kl} / \mathrm{r})$ a un valor máximo de 80 , lo que concuerda razonablemente con la propuesta derivada de esta investigación. Asimismo, Remennikov y Walpole (1998) recomiendan valores entre 80 y 110, y Del Valle (2005) recomienda valores entre 80 y 100.

La recomendación anterior tiene como objetivo que los contravientos, que son susceptibles a pandeo, se diseñen empleando relaciones de esbeltez $(\mathrm{kl} / \mathrm{r})$ tales que, una vez que la estructura sea sometida a una acción dinámica, como la de un sismo, su comportamiento cíclico sea lo más estable posible, conforme a las premisa de diseño y comportamiento esperado. 


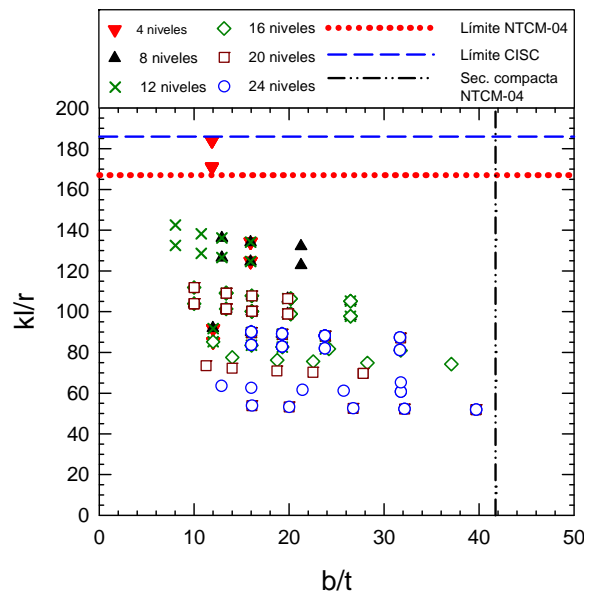

Figura 26. Relaciones ancho-grueso $(b / t)$ contra relaciones de esbeltez en las secciones empleadas en contravientos

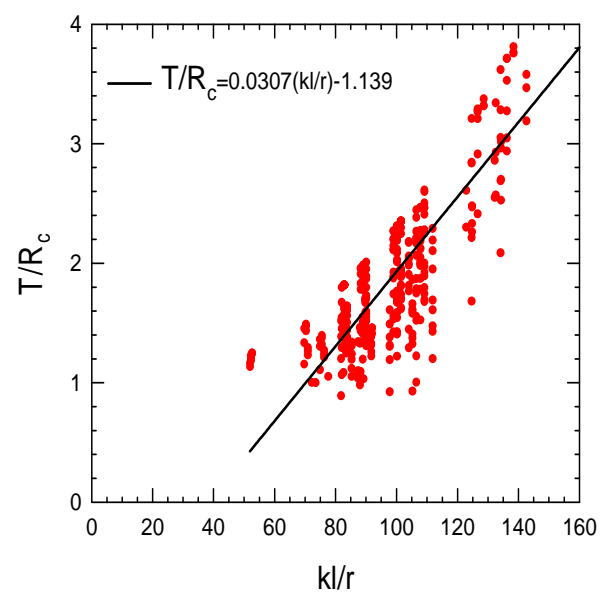

Figura 27. Relación entre la fuerza de tensión normalizada $(T)$ respecto a la carga de pandeo $\left(R_{c}\right)$ y la relación de esbeltez en las diagonales de contraventeo $(\mathrm{kl} / \mathrm{r})$

\section{COMENTARIOS FINALES}

Se presentó la primera etapa de un estudio en que se evalúa, mediante análisis estáticos no lineales ante carga monótona creciente, el comportamiento de marcos dúctiles de concreto reforzado con contraventeo metálico tipo chevrón de entre cuatro y 24 niveles ubicados en la zona del lago del Distrito Federal. El estudio se enfocó en la obtención de parámetros de diseño específicos del sistema estructural estudiado. Con base en el conjunto de resultados analíticos obtenidos, se proponen algunos parámetros específicos para el diseño de estructuras nuevas con comportamiento dúctil, como son: distorsiones de fluencia, distorsiones para el estado de prevención de colapso, factores de reducción por sobrerresistencia, aporte mínimo de las columnas al cortante del sistema resistente ante carga lateral, así como observaciones y recomendaciones de diseño a nivel elemento.

De los resultados expuestos, se pueden hacer los siguientes comentarios y observaciones:

(1) Es posible realizar diseños dúctiles de estructuras nuevas con base en marcos de concreto reforzado y contraventeo chevrón empleando algunas recomendaciones actualmente establecidas en los códigos de diseño, siempre y cuando se empleen conceptos de diseño por capacidad, siguiendo un proceso secuencial de acuerdo al mecanismo de falla esperado, es decir, en primera instancia debe diseñarse la rigidez y resistencia del sistema de contraventeo, posteriormente las vigas, y finalmente debe realizarse el diseño de las columnas y las conexiones para revisar la integridad de los nudos.

(2) Si se emplea una metodología de diseño por capacidad conforme a lo indicado en el punto anterior, es factible obtener mecanismos de colapso cercanos al supuesto de columna fuerte viga débil - contraviento más débil, y capacidades de deformación y de sobrerresistencia razonables para los modelos de baja y mediana altura (cuatro a 16 niveles) cuando las columnas de los marcos contribuyen por lo menos con el $50 \%$ de la resistencia a fuerza cortante del entrepiso. Estos resultados respaldan a la disposición general de las NTCS-04 de limitar la 
participación de los contravientos para aportar hasta un 50\% de la resistencia a cortante en marcos dúctiles.

(3) La estrategia empleada para limitar la carga axial máxima en el proceso de diseño de las columnas, con la finalidad de garantizar una capacidad de rotación mínima en la zona de formación de articulaciones plásticas, parece razonable, al menos para los modelos de baja y mediana altura (cuatro a 16 niveles).

(4) Se observa una relación entre los factores de reducción por sobrerresistencia $(R)$ calculados y el porcentaje que las columnas aportan al cortante resistente. A medida que dicho porcentaje se incrementa, los factores $R$ disminuyen. Dicho efecto es más notorio en las estructuras bajas (cuatro y ocho niveles) que en las de mayor altura.

(5) Se propone una expresión para el cálculo de los factores de reducción por sobrerresistencia $(R)$, la cual se deriva de los resultados de los análisis estáticos no lineales.

(6) Se propone una distorsión asociada a la fluencia $\Delta_{y}=0.002$ para la revisión del estado límite de servicio.

(7) Se propone una distorsión máxima de diseño igual a $\Delta_{\max }=0.013$ para la revisión del estado límite de prevención de colapso. Es importante hacer notar que el valor propuesto es inferior a lo actualmente recomendado en algunos códigos internacionales y en el Apéndice A de las NTCS-04 $\left(\Delta_{\max }=0.015\right)$, por lo que en la siguiente etapa de este estudio se valora cuál de los dos límites resulta más adecuado para el diseño de estos sistemas estructurales.

(8) Se estudió el efecto de la altura y la relación de esbeltez en el comportamiento estructural. Se observó que para los modelos de mayor altura (20 y 24 niveles) es necesario un ajuste en la metodología de diseño para prevenir la formación de articulaciones plásticas indeseables en las columnas de los niveles inferiores. Una estrategia sugerida para evitar esto es establecer un límite superior en el porcentaje de resistencia a fuerza cortante mínimo que las columnas de un entrepiso deben aportar para resistir las demandas sísmicas, así como incrementar en $30 \%$ la carga axial de diseño de columnas de esquina y de borde de los niveles inferiores en el caso de estructuras esbeltas $(H / L>2.5)$. De los mapeos de rotaciones plásticas acumuladas, se observó que las columnas centrales presentan un comportamiento satisfactorio. Además, la carga axial en las columnas centrales, a diferencia de lo observado en algunas columnas de borde, no excede su capacidad. Lo anterior debido en gran medida a que las cargas axiales por sismo en las columnas centrales, dada su ubicación geométrica en el marco, son notablemente menores que en las columnas periféricas (de borde y/o esquina, Godínez 2010).

(9) Con lo finalidad de obtener mecanismos de colapso congruentes con la filosofía de diseño, es decir, columnas fuerte-viga débil-contraviento más débil, se propone una ecuación simple en función de la relación de esbeltez de la estructura $(H / L)$, para la estimación del porcentaje de resistencia a fuerza cortante mínimo que las columnas deben aportar a la resistencia total.

(10) Se propone una expresión simple para la estimación de los periodos fundamentales de vibrar de estructuras con base en marcos de concreto reforzado con contravientos metálicos en configuración chevrón en función del número de niveles de la estructura o, en su caso, en función de la altura de la misma. 
(11) Con base en el estudio a nivel local de contravientos, vigas y columnas, es posible hacer las siguientes observaciones y propuestas: (a) para el diseño de los elementos de contraventeo se recomienda el empleo de relaciones de esbeltez máximas comprendidas en el intervalo de $80 \mathrm{y}$ 100 ( $80 \leq k L / r \leq 100$ ), (b) la metodología de diseño por capacidad para el diseño por flexión y cortante de las vigas es adecuada (metodología considerada en las NTCC-04), (c) en general, la metodología empleada para el diseño por flexocompresión de las columnas es adecuada. En el caso de estructuras esbeltas $(H / L>2.5)$ se recomienda que la carga axial de diseño de las columnas de esquina o de borde de los primeros niveles se incremente en $30 \%$. Asimismo, se observó que una falla por cortante es poco probable, por tanto, tal y como se ha sugerido en el caso de estructuras con base en marcos momento-resistentes, y con la finalidad de optimizar los diseños, sería recomendable realizar estudios analíticos más amplios que el que aquí se presenta, acompañados de un programa experimental en que se evalúe si los criterios de diseño empleados son conservadores o no. Dichos estudios podrían conducir a recomendaciones de diseño con respaldo tanto analítico como experimental.

Los resultados reportados requieren de análisis adicionales para evaluar su eficiencia en cuanto a las mejoras en el diseño de marcos dúctiles de concreto reforzado con contraventeo metálico tipo chevrón. Con este fin, en una etapa posterior del estudio se evaluó el comportamiento de edificios diseñados conforme a las propuestas realizadas en este artículo. La evaluación del comportamiento de los edificios diseñados se realizó mediante análisis dinámicos no lineales paso a paso, empleando registros acelerométricos o artificiales que representen el peligro sísmico actualmente considerado en los códigos de diseño del país, y los resultados más interesantes se reportarán en breve (Godínez et al. 2012).

\section{AGRADECIMIENTOS}

El primer autor agradece la beca de Conacyt que le permitió solventar por cuatro años sus estudios e investigación doctorales. Los autores agradecen a la Dirección de Obras del Gobierno del Distrito Federal por el pequeño patrocinio complementario en la fase final de esta investigación. Se agradecen ampliamente los comentarios y sugerencias de los revisores anónimos, los cuales ayudaron a mejorar la calidad de este artículo.

\section{REFERENCIAS}

ACI 318-08 (2008), "Building code requirements for structural concrete (ACI-318-08) and commentary", Farmington Hills. (MI, USA) American Concrete Institute.

ASCE 7-05 (2005), "Minimum design loads for buildings and other structures", ASCE Standard ASCE/SEI 7-05, American Society of Civil Engineers, ISBN 0-7844-0809-2.

Badoux, M y J Jirsa (1990), "Steel bracing of RC frames for seismic retrofitting", ASCE Journal of Structural Engineering, Vol. 116, No. 1, enero, pp. 55-74.

Black, R, W Wenger y E Popov (1980), "Inelastic buckling of steel struts under cyclic load reversals" Reporte No. UCB/EERC-80/40, Department of Civil Engineering, University of California at Berkeley.

Bruneau, M, C Uang y A Whittaker (1998), "Ductile design of steel structures", segunda edición, McGraw-Hill, New York. 
Castro, F, C Palacios y S M Alcocer (2005), "Consideraciones en el diseño de estructuras a base de marcos de concreto reforzado para asegurar el mecanismo plástico columna fuerte - viga débil", Memorias, XV Congreso Nacional de Ingeniería Sísmica, México, artículo VIII-09, CD-ROM, septiembre.

Chopra, A K y R K Goel (2001), “A modal pushover analysis procedure to estimate seismic demands for buildings: Theory and preliminary evaluation", Reporte No. PEER 2001-03, Pacific Earthquake Engineering Research Center.

Chopra, A K y R K Goel (2002), "A modal pushover analysis for estimating seismic demands of buildings", Earthquake Engineering and Structural Dynamics, Vol. 31, pp. 561-582.

CISC-08 (2008), “Canadian Institute of Steel Construction, Handbook”, Novena edición, Canada.

Downs, R E, K D Hjelmstad y D A Foutch (1991), "Evaluation of two RC buildings retrofit with steel bracing", Structural Research Series No. 563, Department of Civil Engineering, University of Illinois at Urbana-Champaign.

Del Valle, E, D A Foutch, K D Hjelmstad, E Figueroa y A Tena (1988), "Seismic retrofit of a RC building: a case study", Memorias, 9th World Conference on Earthquake Engineering, TokyoKyoto, Japón, Vol. VII, pp. 451-456.

Del Valle, E (2005), Comunicación personal.

Elghazouli, A (2003), "Seismic design procedures for concentrically braced frames", Structures and Buildings, 156 Issue SB4. EBSCO host, Research Databases, http://search.epnet.com/community.aspx.

Foutch, DA, K D Hjelmstad, E Del Valle, E Figueroa y R E Downs (1989), "The Mexico earthquake of September 19, 1985. Case studies of seismic strengthening for two buildings in Mexico City", Earthquake Spectra, Vol. 5, No 1, noviembre, pp. 153-174.

FEMA-273 (1997), "NEHRP guidelines for the seismic rehabilitation of buildings. FEMA publication 273". Washington, DC: Federal Emergency Management Agency, Octubre.

Fuentes, L R (2000), "Modelos calibrados de un edificio instrumentado", Tesis de Maestría, División de Estudios de Posgrado de la Facultad de Ingeniería, Universidad Nacional Autónoma de México, noviembre.

Ghaffarzadeh, H y M R Maheri (2006), "Cyclic tests on internally braced frames", Journal of Seismology and Earthquake Engineering, Vol. 8, No. 3, pp. 177-186.

Ghobarah, A y H Abou-Elfath (2001), "Rehabilitation of a reinforced concrete frame using eccentric steel bracing”, Engineering Structures, Vol. 23, pp. 745-755.

Godínez, E A y A Tena (2007), "Evaluación de los criterios de diseño sísmico del RCDF para marcos dúctiles de concreto reforzado con contravientos", Memorias, XVI Congreso Nacional de Ingeniería Sísmica, Ixtapa, Guerrero, CD-ROM.

Godínez, E A y A Tena (2008), "Behavior of moment resisting reinforced concrete concentric braced frames (RC-MRCBFs) in seismic zones", Memorias, 14th World Conference on Earthquake Engineering, Beijing, China, Octubre.

Godínez, E A y A Tena (2009), "Propuesta de diseño de marcos dúctiles de concreto reforzado con contraventeo chevrón con base en los resultados de análisis no lineales", Memorias, XVII Congreso Nacional de Ingeniería Sísmica, Puebla, Puebla, CD-ROM. 
Godínez, E A y A Tena (2010), "Nonlinear behavior of code-designed reinforced concrete concentric braced frames under lateral loading", Engineering Structures, Vol. 32, pp. 944-963.

Godínez, E A (2010), "Estudio del comportamiento de marcos dúctiles de concreto reforzado con contraventeo chevrón", Tesis de Doctorado, Posgrado en Ingeniería Estructural, División de Ciencias Básicas e Ingeniería, Universidad Autónoma Metropolitana Azcapotzalco, julio.

Godínez, E A y A Tena (2011), "Estudio de las particularidades de las curvas cortante-distorsión de marcos dúctiles de concreto reforzado con contraventeo chevrón", aceptado para publicación en Revista internacional de Ingeniería de Estructuras (en prensa).

Godínez, E A, A Tena y L E Pérez (2012), "Comportamiento sísmico de edificios con base en marcos dúctiles de concreto reforzado con contraventeo chevrón”, Aceptado para publicarse en Revista de Ingeniería Sísmica.

Goel, R K y A K Chopra (2004), "Evaluation of modal and FEMA pushover analyses: SAC Buildings", Earthquake Spectra, Vol. 20, No. 1, pp. 225-254.

Horvilleur, J F y M A Cheema (1994), "Análisis lateral de marcos de concreto reforzado sometidos a cargas laterales sísmicas", Memorias, IX Congreso Nacional de Ingeniería Estructural, Zacatecas, Zacatecas, Vol. I, pp. 244-259, octubre.

Ikeda, K y S Mahin (1984), "A refined physical theory for predicting the seismic behavior of braced steel frames" Reporte No. UCB/EERC-84/12, Department of Civil Engineering, University of California at Berkeley.

Kemp, R A (1996), "Inelastic local and lateral buckling in design codes", Journal of Structural Engineering ASCE, Vol. 122, No. 4, abril, pp. 374-382.

Khatib, I, S Mahin y K Pister (1988), "Seismic behavior of concentrically braced steel frames" Reporte No. UCB/EERC-88/01, Earthquake Engineering Research Center, University of California at Berkeley.

LRFD-01 (2001), "Manual of Steel Construction. Load Resistance Factor Design. Specification for Structural Steel Buildings", American Institute of Steel Construction (AISC).

Luna, J L y A Tena (2002), "Observaciones sobre algunos criterios de diseño sísmico de edificios con marcos de concreto reforzado", Revista de Ingeniería Sísmica, SMIS, No. 66, enero-junio, pp. 1-43.

Maheri, M R y R Akbari (2003). "Seismic behaviour factor, R, for steel X-braced and knee-braced RC buildings", Engineering Structures, Vol. 25, pp. 1505-1513.

Maheri, M R y A Hadjipour (2003). "Experimental investigation and design of steel brace connection to RC frame”, Engineering Structures, Vol. 25, pp. 1707-1714.

Maheri, M R y H Ghaffarzadeh (2008), "Connection overstrength in steel-braced RC frames", Engineering Structures, Vol. 30, pp. 1938-1948.

Masri, A y S Goel (1996), "Seismic design and testing of an RC slab-column frame strengthened by steel bracing”, Earthquake Spectra, Vol. 12, No. 4, noviembre, pp. 645-666.

MOC-2008 (2009), Manual de diseño de obras civiles. Diseño de estructuras de edificios, Instituto de Investigaciones Eléctricas, Comisión Federal de Electricidad, México, diciembre.

Murià, D y R González (1995), "Propiedades dinámicas de edificios de la ciudad de México", Revista de Ingeniería Sísmica, SMIS, No. 51, pp. 25-45.

Newmark, N M y W J Hall (1982), “Earthquake spectra and design”, Monograph series, Earthquake Engineering Research Institute. Oakland. 
NTCC-04 (2004), "Normas Técnicas Complementarias para Diseño de Estructuras de Concreto", Gaceta Oficial del Distrito Federal, Tomo II, No. 103-BIS, octubre.

NTCEM-04 (2004), "Normas Técnicas Complementarias para Diseño de Estructuras Metálicas", Gaceta Oficial del Distrito Federal, Tomo II, No. 103-BIS, octubre.

NTCS-2004 (2004) “Normas Técnicas Complementarias para Diseño por Sismo", Gaceta Oficial del Distrito Federal, Tomo II, No. 103-BIS, octubre, pp. 55-77.

Osman, A, A Rashed y M El-Kady (2006), "Seismic response of R.C. frames with concentric steel bracing" Memorias, 8NCEE, San Francisco, California, CDROM, documento 1979, abril.

Remennikov, A y W Walpole (1998), "Seismic behavior and deterministic design procedures for steel Vbraced frames", Earthquake Spectra, Vol. 14, No. 2, pp. 335-355.

SAP 2000 (1999), “SAP 2000 Nonlinear Versión 7.12 Structural analysis program”, Computer and Structures, Inc., Berkeley, California.

Tapia, E y A Tena (2008). "Behavior of moment resisting concentrically braced frames (MRCBFs) of regular buildings in seismic zones". Memorias, 14th World Conference on Earthquake Engineering, Beijing, China, artículo No. 05-05-0008, CD-ROM, octubre.

Tena, A, E Del Valle y D Pérez (1996), "Issues on the seismic retrofit of a building near resonant response and structural pounding", Earthquake Spectra, Vol. 12, No. 3, agosto, pp. 567-597.

Tena, A (2007), “Análisis de estructuras con métodos matriciales”, primera edición, editorial Limusa, ISBN-13:978-968-18-6980-9, septiembre.

Tena, A y H Correa (2008), "Evaluación de los criterios de diseño por sismo del RCDF para marcos dúctiles de concreto reforzado", Revista de Ingeniería Sísmica, SMIS, No. 78, pp. 79-101, enerojunio.

UBC-97 (1997), "Uniform Building Code. 1997 edition", International conference of building officials, Vol. 2.

Wallace, J y J Moehle (1989), "BIAX: A computer program for the analysis reinforced concrete sections" Reporte No. UCB/SEMM-89/12, Department of Civil Engineering, University of California at Berkeley.

Youssef, M A, H Ghaffarzadeh y M Nehdi (2007). "Seismic performance of RC frames with concentric internal steel bracing”, Engineering Structures, Vol. 29, pp. 1561-1568. 